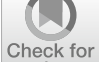

Check for

updates

Cite as

Nano-Micro Lett.

(2020) 12:58

Received: 24 November 2019

Accepted: 31 December 2019

Published online: 18 February 2020

(C) The Author(s) 2020

\section{A Molecular Foaming and Activation Strategy to Porous N-Doped Carbon Foams for Supercapacitors and $\mathrm{CO}_{2}$ Capture}

\author{
Mengyuan Zhou ${ }^{1}$, Yaqian Lin ${ }^{1}$, Huayao Xia ${ }^{1}$, Xiangru Wei ${ }^{1}$, Yan Yao ${ }^{1}$, Xiaoning Wang ${ }^{1}$, \\ Zhangxiong $\mathrm{Wu}^{1} \bowtie$ \\ $\triangle$ Zhangxiong Wu, zhangwu@suda.edu.cn \\ 1 Particle Engineering Laboratory (CPCIA) and Suzhou Key Laboratory of Green Chemical Engineering, \\ School of Chemical and Environmental Engineering, College of Chemistry, Chemical Engineering \\ and Materials Science, Soochow University, Suzhou 2151213, Jiangsu, People's Republic of China
}

\title{
HIGHLIGHTS
}

- An in situ molecular foaming and activation strategy is designed and investigated for the synthesis of hierarchically porous N-doped carbon foams (HPNCFs).

- The prepared HPNCFs possess 3D macropores, uniform micropores and mesopores, ultrahigh surface areas and high $\mathrm{N}$ contents and show high performances in supercapacitors and $\mathrm{CO}_{2}$ capture.
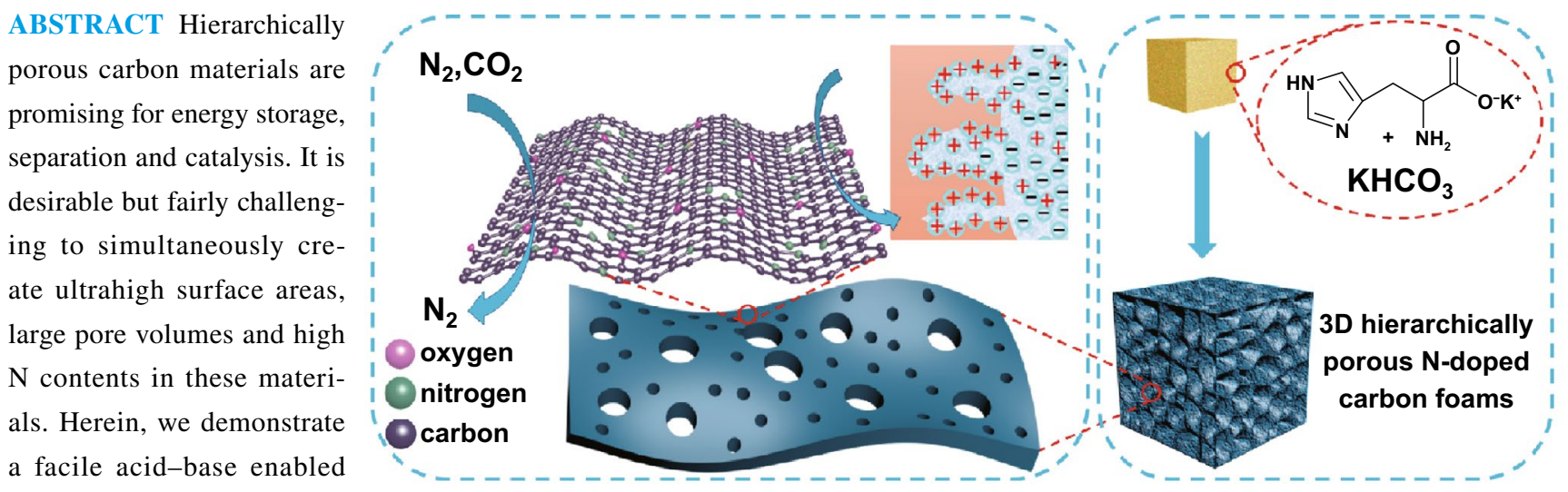
in situ molecular foaming and activation strategy for the synthesis of hierarchically macro-/meso-/microporous N-doped carbon foams (HPNCFs). The key design for the synthesis is the selection of histidine (His) and potassium bicarbonate (PBC) to allow the formation of 3D foam structures by in situ foaming, the PBC/His acid-base reaction to enable a molecular mixing and subsequent a uniform chemical activation, and the stable imidazole moiety in His to sustain high $\mathrm{N}$ contents after carbonization. The formation mechanism of the HPNCFs is studied in detail. The prepared HPNCFs possess 3D macroporous frameworks with thin well-graphitized carbon walls, ultrahigh surface areas (up to $3200 \mathrm{~m}^{2} \mathrm{~g}^{-1}$ ), large pore volumes (up to $2.0 \mathrm{~cm}^{3} \mathrm{~g}^{-1}$ ), high micropore volumes (up to $0.67 \mathrm{~cm}^{3} \mathrm{~g}^{-1}$ ), narrowly distributed micropores and mesopores and high $\mathrm{N}$ contents (up to $14.6 \mathrm{wt} \%$ ) with pyrrolic $\mathrm{N}$ as the predominant $\mathrm{N}$ site. The HPNCFs are promising for supercapacitors with high specific capacitances (185-240 $\mathrm{F} \mathrm{g}^{-1}$ ), good rate capability and excellent stability. They are also excellent for $\mathrm{CO}_{2}$ capture with a high adsorption capacity $\left(\sim 4.13 \mathrm{mmol} \mathrm{g}^{-1}\right)$, a large isosteric heat of adsorption $\left(26.5 \mathrm{~kJ} \mathrm{~mol}^{-1}\right)$ and an excellent $\mathrm{CO}_{2} / \mathrm{N}_{2}$ selectivity $(\sim 24)$.

KEYWORDS Porous carbon foams; Hierarchical pore structure; Nitrogen doping; Supercapacitors; $\mathrm{CO}_{2}$ capture 


\section{Introduction}

Porous carbon materials have received wide interest because of their attractive physicochemical properties, easy compatibility with other elements, and low cost and toxicity, as well as wide applications in energy storage and conversion, adsorption and catalysis [1-7]. A well-controlled pore structure is significantly important for these materials in various applications. Taking supercapacitors and $\mathrm{CO}_{2}$ capture as examples [4, 8-13], which are important for upgrading fossil fuel utilization in a greener and more sustainable way, uniform micropores and high surface areas are desirable to provide abundant active sites for enhanced storage of smallsized ions and gas molecules. However, the accessibility of micropores within thick carbon walls is low, even inaccessible for bulk molecular diffusion $[4,14,15]$. To overcome this limitation, creating mesopores in microporous carbon walls to establish short diffusion paths and large pore volumes is effective, especially so for improving charge storage at a high current density $[16,17]$. In addition, a macroporous network can act as a molecule- or ion-buffering reservoir for shortening diffusion time [14]. Therefore, it is attractive to construct hierarchically macro-/meso-/microporous carbon materials (HPCs) with well-defined structures and ultrahigh surface areas to further enhance their potential.

There are a series of methods reported in the literature for the synthesis of HPCs [18]. Based on the type of precursors adopted, three general methods can be categorized. The first method is the use of preformed carbon nanomaterials, such as graphene, for the construction of low-density HPCs in the form of aerogels $[19,20]$. These materials possess moderate surface areas and lack of control in the micro-/mesopore structure. The second method is carbonization of natural biomass or synthetic polymers [21, 22]. For example, carbonization of natural biomass can result in various interesting HPCs [23-34]. Control of the pore size and distribution in these HPCs is relatively difficult. In addition, their carbon walls are often relatively thick such that the accessibility of the micropores may be restricted. The third method is the templating synthesis starting from molecular precursors [35-38]. Various templates can be adopted to confine the carbonization of different precursors. In particular, the dual templating approach, in which colloid nanospheres and surfactants act as the hard and soft templates, is capable of synthesizing ordered hierarchical structures with uniform and controllable pore sizes [35, 39-42]. Nevertheless, this templating method is complicated, costly and time-consuming. Comparatively, the salt templating approach starting from molecularly mixed precursors and salts, sometimes combining with ice templating, chemical blowing and leavening, is general and cost-effective for generating various HPCs with interesting structures [43-55]. During carbonization of the precursors, the diffusion and growth of the salts or their thermal decomposition products play the templating role generating hierarchical pores. The resulted HPCs often possess broad pore size distributions with variable surface areas. In order to improve the microporosity and surface area of HPCs, post-activation with various chemical activators, especially $\mathrm{KOH}$, is often adopted. A disadvantage for post-activation is the high dosage of activator and the non-uniform mixing between carbon and activator, which can subsequently result in uneven activation and excessive etching. In spite of the above development, it is still fairly challenging to simultaneously create ultrahigh surface areas, uniform micro-/mesopores and large pore volumes in HPCs.

On the other hand, doping of nitrogen $(\mathrm{N})$ in porous carbon materials can increase the electronic conductivity, wettability and basicity, which is highly desirable for supercapacitor and selective $\mathrm{CO}_{2}$ capture [16, 56-60]. There are two major methods for $\mathrm{N}$ doping in carbon materials. The first method is post-treatment under high temperatures by exposing preformed carbon materials in ammonia or other $\mathrm{N}$-containing substances [61, 62]. This method may cause uneven distribution of $\mathrm{N}$ and structure change. The more common method is in situ doping by directly pyrolysis of a single $\mathrm{N}$-containing organic precursor or precursor mixture [35, 60, 63-67]. Although a series of porous N-doped carbon materials have been reported, the construction of threedimensional HPCs with ultrahigh surface areas, large pore volumes, and high $\mathrm{N}$ contents sustained at high carbonization temperatures is still highly demanded.

In this work, we demonstrate an acid-base enabled in situ foaming and activation strategy for the synthesis of hierarchically macro-/meso-/microporous N-doped carbon foams (HPNCFs). Our concept for the synthesis design lies in the following aspects. First, the selected amino acid (His) as the carbon precursor shows a self-foaming behavior under heat treatment, and the selected salt PBC undergoes decomposition releasing $\mathrm{CO}_{2}$ to facilitate the foaming process, allowing the formation of 3D macroporous frameworks with thin walls. Second, the PBC/His acid-base reaction allows a molecular mixing for subsequent in situ uniform 
activation to generate narrowly distributed micropores and mesopores. Third, the imidazole moiety of His allows the sustain of a high $\mathrm{N}$ content after carbonization. The formation mechanism of the HPNCFs is illustrated by a detailed study. The resultant HPNCFs possess attractive properties, including 3D foam structures constructed by thin carbon walls, ultrahigh surface areas $\left(\sim 3200 \mathrm{~m}^{2} \mathrm{~g}^{-1}\right)$, large pore volumes $\left(\sim 2.0 \mathrm{~cm}^{3} \mathrm{~g}^{-1}\right)$, narrowly distributed micropores and mesopores and high $\mathrm{N}$ contents $(\sim 14.6 \mathrm{wt} \%)$. They are promising for supercapacitors showing high specific capacitances, a good rate capability and an excellent stability, as well as attractive for $\mathrm{CO}_{2}$ capture with a large adsorption capacity and an excellent $\mathrm{CO}_{2} / \mathrm{N}_{2}$ selectivity.

\section{Experimental Section}

\subsection{Preparation of HPNCFs}

The HPNCFs were prepared by a simple acid-base enabled in situ foaming and activation method. The details of the chemicals adopted for the synthesis can be found in Supporting Information. Briefly, a certain amount (0.9687-3.8748 g) of PBC was dissolved in deionized water $(100 \mathrm{~mL})$, and then, $2.0 \mathrm{~g}$ of His was added into the above solution. After completely dissolved, the obtained clear solution was transferred to an eggplant-shaped steaming bottle. The solvent was removed at $50{ }^{\circ} \mathrm{C}$ under a reduced pressure of 20-50 mbar in a rotary evaporation unit. The resulted mixture was collected in a ceramic boat and was subject to a thermal treatment in a tube furnace. The sample was heated from room temperature to various target temperatures (400-900 ${ }^{\circ} \mathrm{C}$ ) with a heating speed of $2{ }^{\circ} \mathrm{C} \mathrm{min}^{-1}$ and kept isothermal at the target temperature for $3 \mathrm{~h}$ under flowing $\mathrm{N}_{2}$ atmosphere $\left(\sim 60 \mathrm{~mL} \mathrm{~min}^{-1}\right)$. Then, after natural cooling, the obtained composites were soaked in water at $60{ }^{\circ} \mathrm{C}$ overnight, followed by filtration, washing with deionized water and ethanol several times and drying in a vacuum oven at $60{ }^{\circ} \mathrm{C}$ for $10 \mathrm{~h}$, leading to the final samples, which were denoted as HPNCF-X-Y, where X stands for the molar ratio of $\mathrm{PBC} / \mathrm{His}$, and $\mathrm{Y}$ for the carbonization temperature (in ${ }^{\circ} \mathrm{C}$ ), respectively. A control sample was also prepared by carbonizing pure His without the addition of PBC following the same procedure. The characterization details of the obtained samples are provided in Supporting Information.

\subsection{Electrochemical Tests}

The electrochemical tests were measured on a $\mathrm{CHI} 760 \mathrm{e}$ electrochemical workstation to evaluate the supercapacitor charge storage performance of the HPNCFs. In the measurement system, a Pt plate was used as the counter electrode, and a $\mathrm{Hg} / \mathrm{HgO}$ electrode was served as the reference electrode. The working electrode was fabricated from the mixture of a specific HPNCF sample ( $80 \mathrm{wt} \%$ ), a conductive agent (acetylene black, $10 \mathrm{wt} \%)$ and a binding agent PTFE (10 wt\%). To prepare the working electrode, the mixture was dispersed in $2.5 \mathrm{~mL}$ of ethanol in an ultrasonic cleaner to form a uniform slurry and then was dried at $80{ }^{\circ} \mathrm{C}$ for $2 \mathrm{~h}$ to evaporate the liquid. The dried black powder was pressed onto a neat nickel foam $\left(\sim 1 \times 1 \mathrm{~cm}^{2}\right)$ to obtain a thin electrode membrane. The composite foam was then dried in a vacuum oven at $60{ }^{\circ} \mathrm{C}$ for $12 \mathrm{~h}$. Cyclic voltammetry (CV), galvanostatic charge and discharge (GCD), electrochemical impedance spectroscopy (EIS) and cyclic tests were carried out through a three-electrode system from 0.0 to $-1.0 \mathrm{~V}$ with a $6.0 \mathrm{M} \mathrm{KOH}$ solution as the electrolyte. $\mathrm{CV}$ experiments were conducted under different sweep rates of $5-100 \mathrm{mV} \mathrm{s}^{-1}$. EIS was carried out over a frequency range of $100-0.01 \mathrm{~Hz}$ with a $5.0 \mathrm{mV} \mathrm{AC}$ potential amplitude. The specific capacitance $\left(C_{\mathrm{s}}, \mathrm{F} \mathrm{g} \mathrm{g}^{-1}\right)$ of the work electrode is calculated by using Eq. 1:

$C_{\mathrm{s}}=I \Delta t /(m \Delta V)$

where $I$ stands for the current density $\left(\mathrm{A} \mathrm{g} \mathrm{g}^{-1}\right), \Delta t$ is the discharging time (s), $\Delta \mathrm{V}$ is the potential range in volt and $m$ for the mass ( $\mathrm{g}$ ) of the active HPNCF material, respectively.

\section{3 $\mathrm{CO}_{2}$ Adsorption Tests}

The gas adsorption performance for $\mathrm{CO}_{2}$ and $\mathrm{N}_{2}$ was evaluated by measuring the adsorption/desorption isotherms of single components and 273 and $298 \mathrm{~K}$ on the Micromeritics ASAP 2020 analyzer. The capacity was retrieved from the adsorption isotherms. The adsorption selectivity was calculated by using Henry's law. The isosteric heat of adsorption $\left(\Delta H_{\text {ads }}\right)$ was calculated by using the Clausius-Clapeyron equation (Eq. 2):

$\ln \left(P_{1} / P_{2}\right)=\left(\Delta H_{\text {ads }} / R\right) \times\left(1 / T_{1}-1 / T_{2}\right)$

where $T_{1}$ and $T_{2}(\mathrm{~K})$ are the two temperatures for adsorption isotherms measurement, $P_{1}$ and $P_{2}$ are the pressure points 
on the two isotherms wherein the adsorption capacities are the same.

\section{Results and Discussion}

\subsection{HPNCFs Formation Mechanism}

To synthesize the HPNCFs, an acid-base enabled in situ foaming and activation strategy has been proposed (Scheme 1). To demonstrate the formation mechanism and the unique features of resulted HPNCFs, the synthesis process with its intermediates has been analyzed. First, $\mathrm{PBC}$ and His can partially neutralize each other by the reaction between the bicarbonate ions of $\mathrm{PBC}$ and the carboxylic group of His (Eq. 3, and Scheme 1A, B). This can be validated by the decreased $\mathrm{pH}$ values of the mixed $\mathrm{PBC} /$ His solutions compared with the pure PBC solutions (Fig. $\mathrm{S} 1)$ and the observed $\mathrm{CO}_{2}$ gas bubbling during mixing $\mathrm{PBC}$ and His in water. Such a neutralization reaction renders the molecular mixing of His and PBC (Scheme 1B), further revealed by the formation of a uniform $\mathrm{PBC} / \mathrm{His}$ composite with evenly distributed $\mathrm{C}, \mathrm{O}, \mathrm{N}$ and $\mathrm{K}$ elements (Fig. S2). Such a molecular mixing is beneficial for in situ foaming and chemical activation. The wide-angle XRD pattern of the dried $\mathrm{PBC} / \mathrm{His}$ mixture shows a group of diffraction peaks different from those of the pure $\mathrm{PBC}$ and
His (Fig. S3), indicating the formation of a new phase probably assigned to the potassium salt of His. Next, the solid is subject to heating for in situ foaming, carbonization and chemical activation. During the heating process, sophisticated physicochemical changes are involved. Pure His is stable up to $\sim 270{ }^{\circ} \mathrm{C}$, followed by melting, polymerization and gradual carbonization at increasing temperatures (Fig. 1A, curve a). The $\mathrm{PBC} / \mathrm{His}$ mixture shows a gradual mass loss at $100-270{ }^{\circ} \mathrm{C}$ (Fig. 1A, curve b), attributed to the decomposition of $\mathrm{PBC}$ releasing $\mathrm{CO}_{2}$ and $\mathrm{H}_{2} \mathrm{O}$ as shown in Eq. 4, indicating that the foaming probably starts at about $270{ }^{\circ} \mathrm{C}$. The TG curve of PBC with a weight loss of $\sim 30 \mathrm{wt} \%$ at $100-210{ }^{\circ} \mathrm{C}$ further validates the gas releasing process (Fig. 1A, curve c). This gas formation process may partially overlap with the melting of His, facilitating in situ foaming of the molten/dissolved His liquid (Scheme 1C), leading to the development of a macroporous spongy structure, similar to the leavening process [52]. The optical image after the heating treatment verifies the occurrence of foaming and the formation of a 3D macroporous foam (Fig. 2A). At $270-600{ }^{\circ} \mathrm{C}$, the thermal behaviors of pure His and the $\mathrm{PBC} / \mathrm{His}$ mixture are similar (Fig. 1A, curves a and b), indicating that chemical activation does not obviously occur at this stage. In this stage, condensation of His occurs with continuous weight loss due to the removal of water, $\mathrm{CO}_{2}$ and volatile

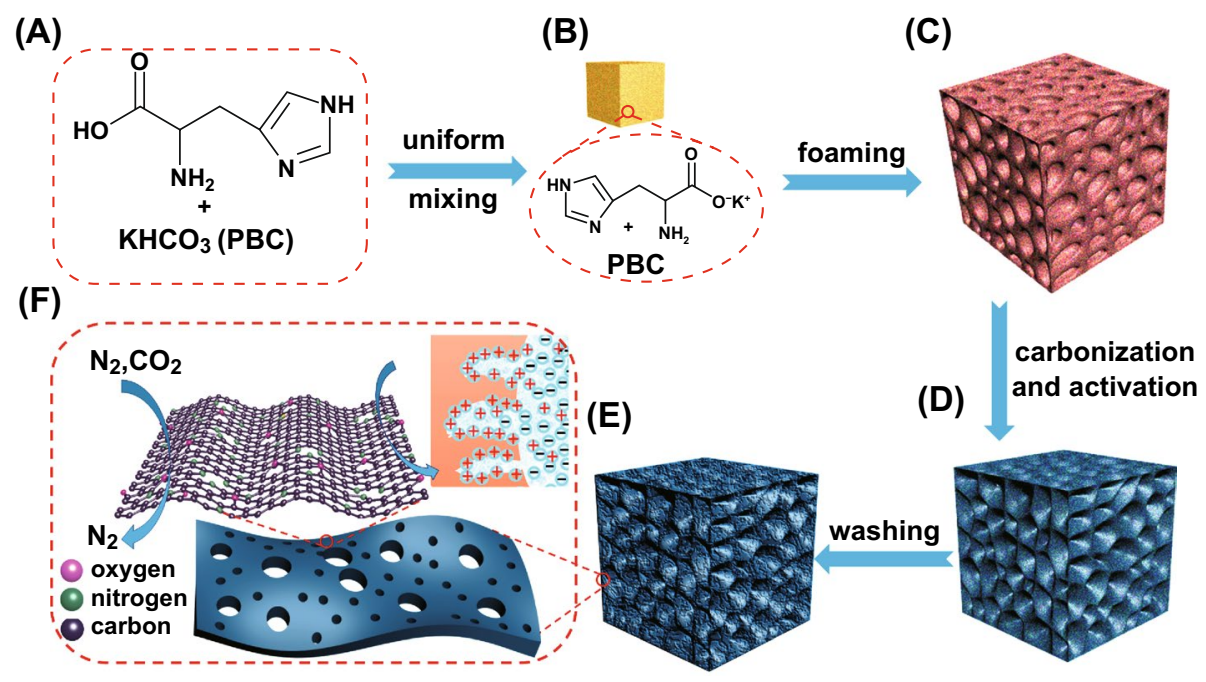

Scheme 1 Schematic illustration of the synthesis process of the HPNCFs: A precursor selection, B the composite obtained after molecular mixing by acid-base reaction, $\mathbf{C}$ the composite obtained after in situ foaming at low temperatures, $\mathbf{D}$ the composite obtained after in situ carbonization and chemical activation at high temperatures, $\mathbf{E}$ the HPNCFs obtained after washing by water, and $\mathbf{F}$ structure model of the HPNCFs and their applications in $\mathrm{CO}_{2} / \mathrm{N}_{2}$ separation and charge storage 

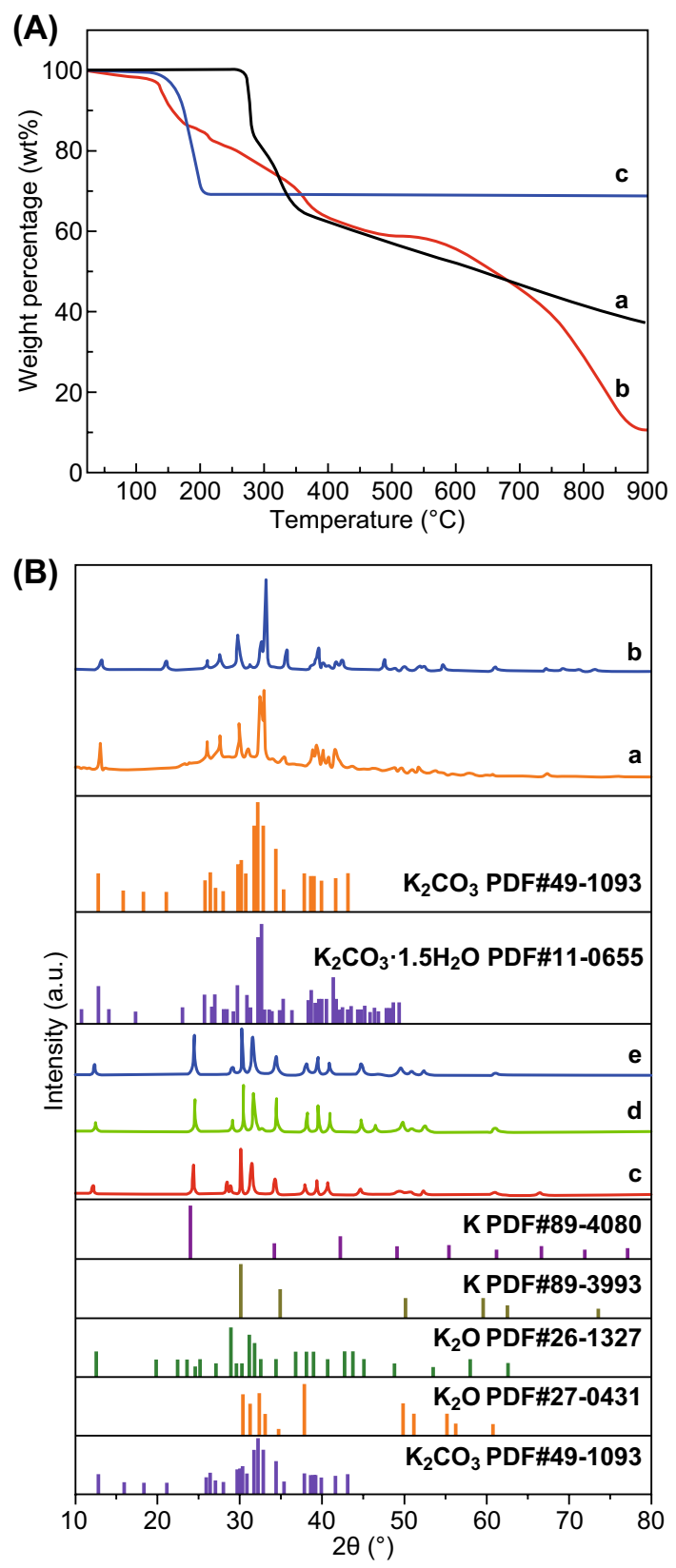

Fig. 1 A TG curve under $\mathrm{N}_{2}$ of the pure His (a), PBC/His mixture with a molar ratio of 2.0 (b) and pure $\mathrm{PBC}$ (c). B Wide-angle XRD patterns of the composites obtained by heating the $\mathrm{PBC} / \mathrm{His}$ mixture with a molar ratio of 2.0 at 400 (a), 600 (b), 700 (c), 800 (d) and $900{ }^{\circ} \mathrm{C}(\mathrm{e})$

$\mathrm{N}$-containing molecular fragments. These released gases can lead to increased porosity in the 3D foams. The wideangle XRD pattern of the composite obtained at $400{ }^{\circ} \mathrm{C}$ reveals the formation of a $\mathrm{K}_{2} \mathrm{CO}_{3} \cdot 1.5 \mathrm{H}_{2} \mathrm{O}$ phase (JCPDS No. 11-0655) (Fig. 1B, curve a), indicating the decomposition of $\mathrm{PBC}$. At a temperature of $600{ }^{\circ} \mathrm{C}$, two crystalline phases assigned to $\mathrm{K}_{2} \mathrm{CO}_{3} \cdot 1.5 \mathrm{H}_{2} \mathrm{O}$ and $\mathrm{K}_{2} \mathrm{CO}_{3}$ (JCPDS No. 49-1093) (Fig. 1B, curve b) can be observed. The $\mathrm{C}, \mathrm{N}, \mathrm{O}$, and $\mathrm{K}$ elements are still uniformly distributed in the composite (Fig. S4a-c). The FTIR spectra of the composites obtained at 400 and $600{ }^{\circ} \mathrm{C}$ show several bands $\sim 2950,2450,1430,840$, and $710 \mathrm{~cm}^{-1}$ (Fig. S5a, b), indicating the presence of $\mathrm{K}_{2} \mathrm{CO}_{3}$. In the temperature range of $700-900{ }^{\circ} \mathrm{C}$, the TG curves of pure His and the $\mathrm{PBC} /$ His derived mixture are significantly different (Fig. 1A, curves a and $\mathrm{b}$ ), because dramatic chemical activation occurs at this stage with the carbonaceous walls becoming increasingly thinner (Scheme 1D). At a temperature of $700-900{ }^{\circ} \mathrm{C}$, His can be carbonized. Meanwhile, potassium oxide $\left(\mathrm{K}_{2} \mathrm{O}\right)$ can be formed because of the decomposition of $\mathrm{K}_{2} \mathrm{CO}_{3}$ and the reaction of $\mathrm{K}_{2} \mathrm{CO}_{3}$ with carbon as shown in Eqs. 5 and 6. The produced $\mathrm{K}_{2} \mathrm{O}$ and $\mathrm{CO}_{2}$ can in situ react with carbon as shown in Eqs. 7 and 8, generating plenty of small pores and potassium (K). The $\mathrm{K}$ vapor can diffuse into the carbon matrix and intercalated into graphitic layers, leading to continuous reaction with oxygen-containing carbon walls. The wide-angle XRD patterns of the composites obtained at $700-900{ }^{\circ} \mathrm{C}$ show the formation of various crystalline phases including $\mathrm{K}_{2} \mathrm{O}$ (JCPDS Nos. 26-1327 and 27-0431), K (JCPDS Nos. 89-3993 and 89-4080) and $\mathrm{K}_{2} \mathrm{CO}_{3}$ (minor) (Fig. 1B, curves c-e), confirming the occurrence of dramatic chemical activation. It should be pointed out that further decomposition of $\mathrm{K}_{2} \mathrm{CO}_{3}$ decomposed from pristine $\mathrm{PBC}$ cannot be observed at $700-900{ }^{\circ} \mathrm{C}$ for pure PBC (69 wt\% remained, Fig. 1A, curve c), indicating that the presence of carbon can promote the decomposition of $\mathrm{K}_{2} \mathrm{CO}_{3}$ into $\mathrm{K}_{2} \mathrm{O}$ and $\mathrm{K}$. From the $\mathrm{PBC} / \mathrm{His}$ mixture with a molar ratio of 2.0 , a low residual of only $\sim 10.4 \mathrm{wt} \%$ at $900{ }^{\circ} \mathrm{C}$ confirms the formation and escape of $\mathrm{K}$ vapor. The elements are still uniformly distributed in the composites obtained at 700-900 ${ }^{\circ} \mathrm{C}$ (Fig. S4d-f), indicating that uniform chemical activation can be achieved. The FTIR spectra of the composites obtained at $700-900{ }^{\circ} \mathrm{C}$ show that the bands attributed to $\mathrm{K}_{2} \mathrm{CO}_{3}$ become weakened (Fig. S5c-e), in accordance with the result that $\mathrm{K}_{2} \mathrm{CO}_{3}$ can be converted to $\mathrm{K}_{2} \mathrm{O}$ and $\mathrm{K}$ in this temperature range. Interestingly, $\mathrm{N}_{2}$ sorption results show that the composites obtained at $400-900{ }^{\circ} \mathrm{C}$ possess no detectable porosity (Scheme 1D, Fig. S6a, b). This is mostly because the generated pores in the carbon walls by activation are occupied by $\mathrm{K}, \mathrm{K}_{2} \mathrm{O}$ and other salts, verifying the occurrence of in situ molecular level 

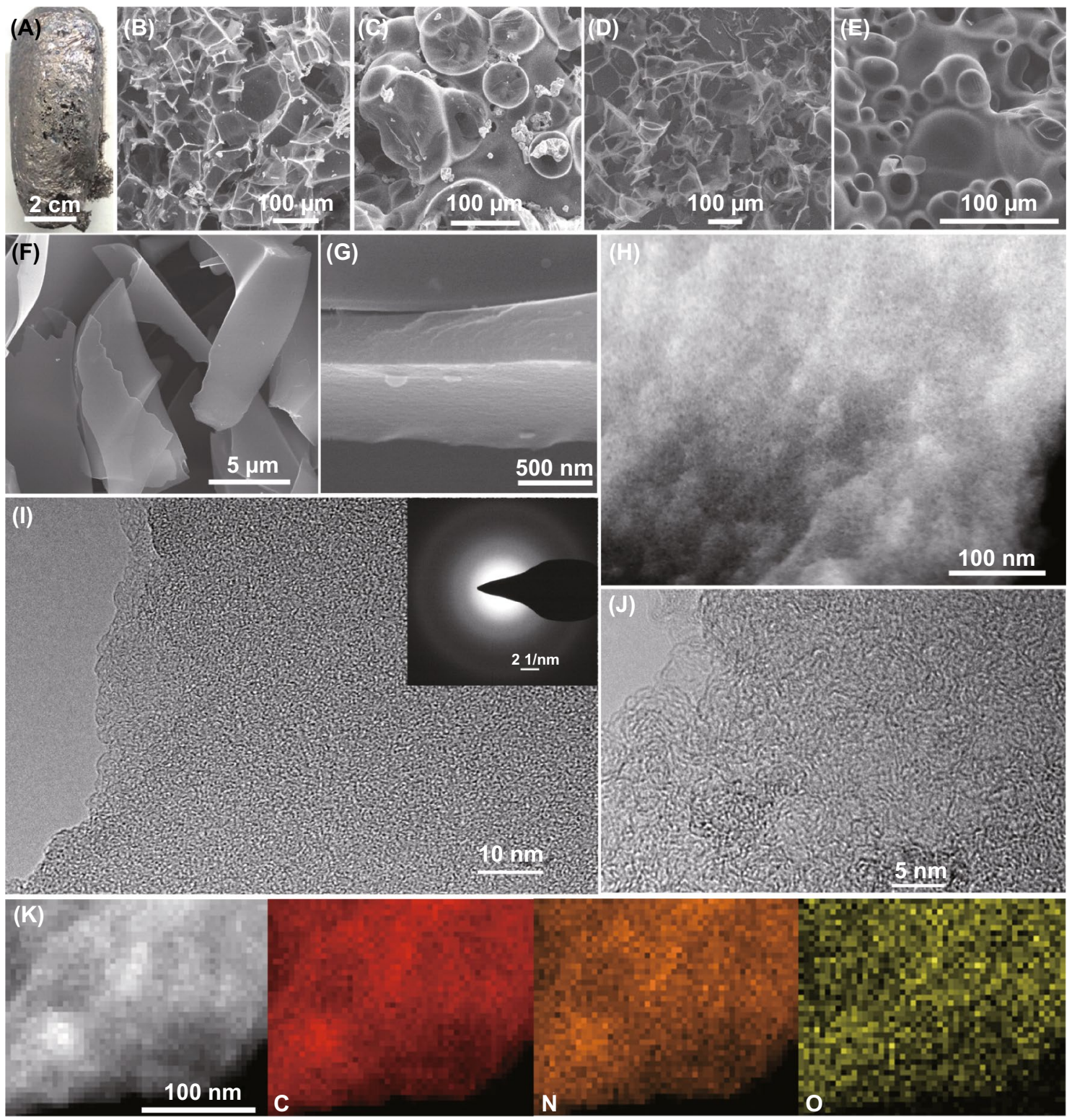

Fig. 2 A Optical, B-G SEM, H DF-STEM, I TEM, inset I SAED pattern, J HRTEM, and K elemental maps of the HPNCF-2.0-900 sample before (A-C) and after (D-K) water washing

activation. SEM images confirm the formation of a foam structure in the composite obtained at $900{ }^{\circ} \mathrm{C}$, with the presence of a 3D macroporous structure inside and hollow carbon capsules on the surface originating from gas foaming (Fig. 2B, C). Finally, washing with water results in the HPNCFs (Scheme 1E). The foam structures are well maintained (Fig. 2D, E). Moreover, due to the presence of an imidazole moiety in His, a high $\mathrm{N}$ content $(6.31 \mathrm{wt} \%)$ can be sustained even at $900{ }^{\circ} \mathrm{C}$. The HPNCFs are suitable for supercapacitors and $\mathrm{CO}_{2}$ adsorption (Scheme $1 \mathrm{~F}$ ). The $3 \mathrm{D}$ macropores act as buffer reservoirs for guest molecules, the mesopores enhance mass transfer, and the micropores and $\mathrm{N}$ sites offer high specific surface areas and abundant active sites.

$$
\begin{aligned}
& \mathrm{C}_{6} \mathrm{H}_{9} \mathrm{~N}_{3} \mathrm{O}_{2}+\mathrm{KHCO}_{3} \rightarrow \mathrm{C}_{6} \mathrm{H}_{8} \mathrm{~N}_{3} \mathrm{O}_{2} \mathrm{~K}+\mathrm{CO}_{2}+\mathrm{H}_{2} \mathrm{O} \\
& 2 \mathrm{KHCO}_{3} \rightarrow \mathrm{K}_{2} \mathrm{CO}_{3}+\mathrm{CO}_{2}+\mathrm{H}_{2} \mathrm{O}
\end{aligned}
$$




$$
\begin{aligned}
& \mathrm{K}_{2} \mathrm{CO}_{3} \rightarrow \mathrm{K}_{2} \mathrm{O}+\mathrm{CO}_{2} \\
& \mathrm{~K}_{2} \mathrm{CO}_{3}+\mathrm{C} \rightarrow \mathrm{K}_{2} \mathrm{O}+2 \mathrm{CO} \\
& \mathrm{K}_{2} \mathrm{O}+\mathrm{C} \rightarrow 2 \mathrm{~K}+\mathrm{CO} \\
& \mathrm{CO}_{2}+\mathrm{C} \rightarrow 2 \mathrm{CO}
\end{aligned}
$$

\subsection{Morphology and Structure of HPNCFs}

All the HPNCFs possess a 3D hierarchically macro-/meso-/ microporous structure. By using the sample HPNCF-2.0900 obtained with a PBC/His molar ratio of 2.0 at $900{ }^{\circ} \mathrm{C}$ as a typical example, the wide-angle XRD pattern shows two weak and broad diffraction peaks at $\sim 25$ and $44^{\circ}$ corresponding to (002) and (100)/(101) planes of graphitized carbon (Fig. 3A, curve a). No other peaks can be detected, implying that the K-containing substances can be washed off by water. The Raman spectrum of the sample displays two distinct bands at $\sim 1341 \mathrm{~cm}^{-1}$ (D band) and $\sim 1586 \mathrm{~cm}^{-1}$ (G band) (Fig. 3B, curve a). The first one can be assigned to carbon of amorphous or defective nature, and the second one to $s p^{2}$ hybridized carbon of graphitic nature. The intensity ratio of the $\mathrm{D}$ and $\mathrm{G}$ bands $\left(I_{\mathrm{D}} / I_{\mathrm{G}}\right)$ is 0.97 , indicating a good graphitization degree. The sample shows a 3D foam morphology with interconnected macropores inside and some hollow carbon capsules on the surface (Fig. 2D, E). The carbon skeleton is made up of thin and smooth carbon plates (Fig. 2F). The thickness of the carbon plates is down to $\sim 300 \mathrm{~nm}$ (Fig. 2G). Such an open 3D thin foam structure accounts for the ultralow density (about $0.03 \mathrm{~g} \mathrm{~cm}^{-3}$ ) of the sample. TEM and dark-field scanning TEM (DF-STEM) images show the presence of uniform micropores and small mesopores within the carbon plates (Fig. $2 \mathrm{H}$, I), which are originating from the etching of carbon by chemical activation. The micropores are in a highly disordered orientation, and they are distributed uniformly throughout the carbon plates because of the in situ chemical activation. HRTEM image shows that very short and randomly orientated (002) graphitic layers with a d-spacing of $\sim 0.37 \mathrm{~nm}$ can be observed (Fig. 2J). Two very weak diffraction rings indexed to the (002) and (101) crystal plate of graphitic carbon can be observed in the selected area electron diffraction (SAED) pattern (inset in Fig. 2I), further indicating that the carbon walls are moderately graphitized.

Heat treatment at $700-900{ }^{\circ} \mathrm{C}$ with a fixed $\mathrm{PBC} / \mathrm{His}$ molar ratio of 2.0 does not obviously influence the overall morphology and structure of the resultant HPNCFs. An obvious difference is that the thickness of carbon plates becomes thinner with the increase in temperature (Fig. 4A, B, and $2 \mathrm{~F})$. This can be explained by two facts. The first one is that the carbon yield of His decreases sharply with the increase in temperature. The second one is that the chemical activation becomes increasingly violent at higher temperatures. The wide-angle XRD patterns show that the sample obtained at $800{ }^{\circ} \mathrm{C}$ possesses the best resolved (002) diffraction peak (Fig. 3A). This is because a higher temperature induces better carbonization, but also triggers more intensive chemical activation increasing structure disorder. The medium temperature of $800{ }^{\circ} \mathrm{C}$ balances the two factors leading to the most carbonized walls. The Raman spectra of the samples obtained at $700-900{ }^{\circ} \mathrm{C}$ are similar, with the lowest $I_{\mathrm{D}} / I_{\mathrm{G}}$ ratio observed for the sample obtained at $700{ }^{\circ} \mathrm{C}$ (Fig. 3B), which is due to the more intensive activation at higher temperatures causing loss of graphitic order.

$\mathrm{PBC} / \mathrm{His}$ molar ratios of $0.75-2.5$ with the fixed temperature of $900{ }^{\circ} \mathrm{C}$ also have no obvious influence on the overall morphology and structure of the resultant HPNCFs. There is also a general trend that the carbon plates become increasingly thinner with the increase in PBC dosage (Fig. 4C-F). This is because of the decreased carbon yield and the more violent chemical activation with higher PBC dosages. The wide-angle XRD patterns show that the intensity of the (002) diffraction peak decreases with the increase in the $\mathrm{PBC} / \mathrm{His}$ ratio (Fig. S7A), because the enhanced chemical activation can result in increased carbon etching. The Raman spectra show a general increasing trend for the $I_{\mathrm{D}} / I_{\mathrm{G}}$ ratio with the increase in the $\mathrm{PBC} / \mathrm{His}$ ratio (Fig. $\mathrm{S} 7 \mathrm{~B}$ ), further revealing that the enhanced chemical activation reduces graphitic order.

\subsection{Textural Properties}

All the HPNCFs possess ultrahigh surface areas, high micropore surface areas, large pore volumes and narrowly distributed micropores and small mesopores (Fig. 5 and Table 1). The representative sample HPNCF-2.0-900 displays $\mathrm{N}_{2}$ adsorption/desorption isotherms of combinative 
(A)

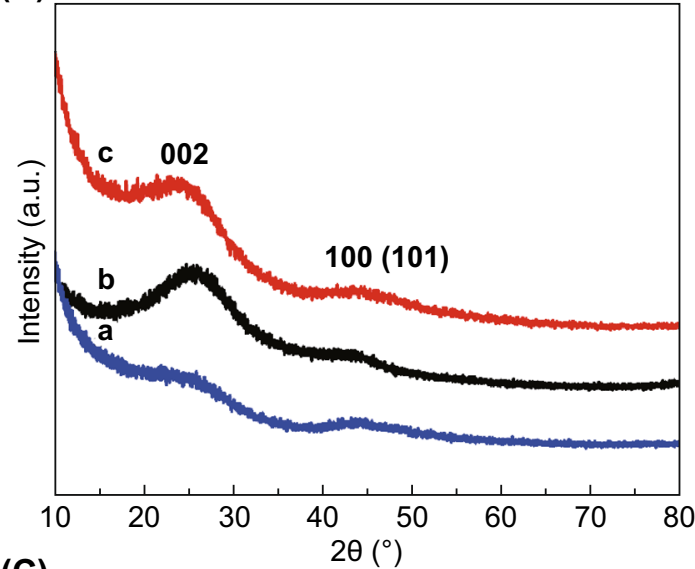

(C)

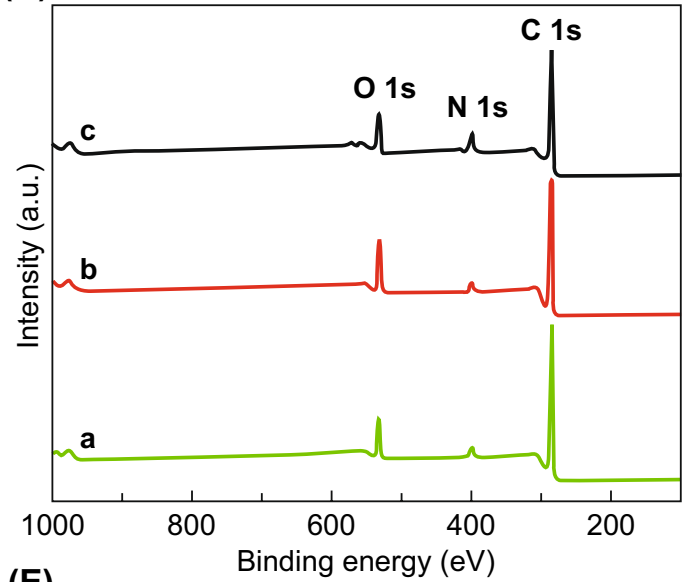

(E)

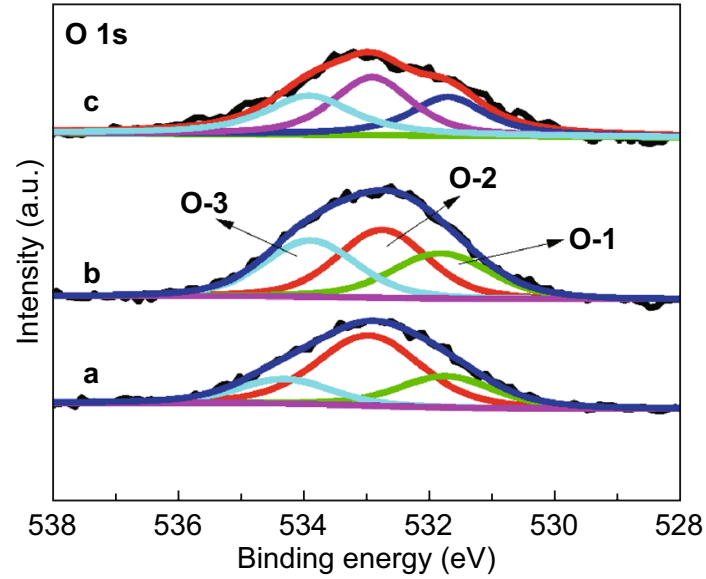

(B)
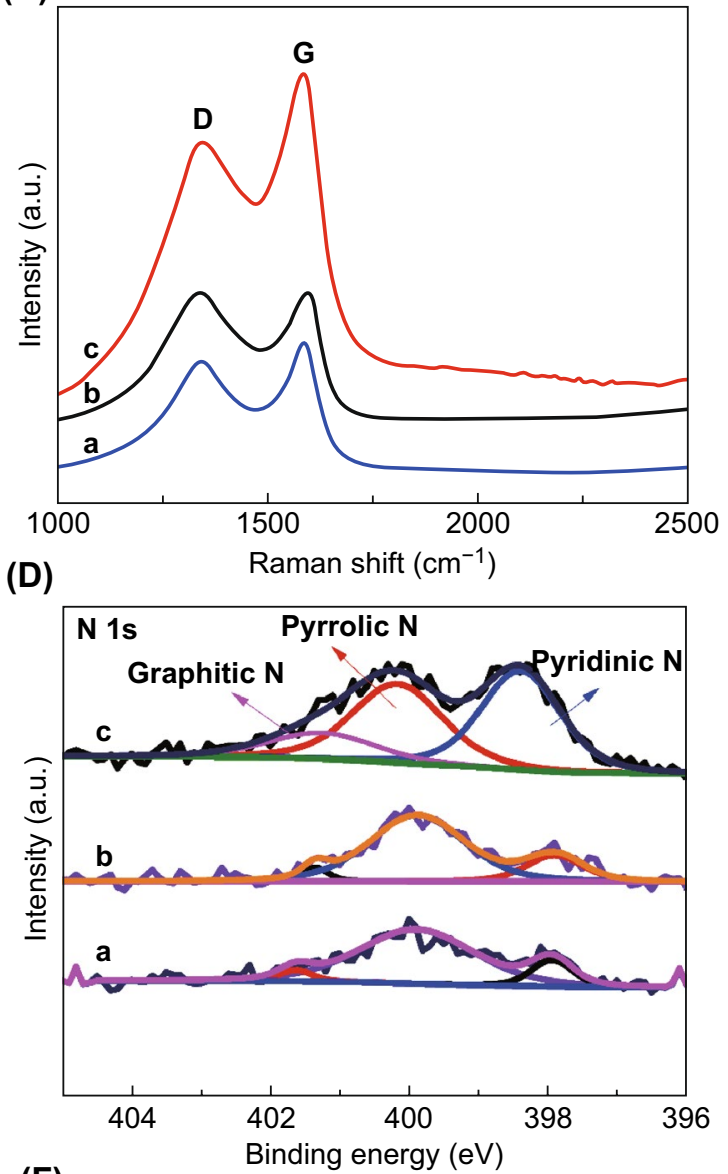

(F)

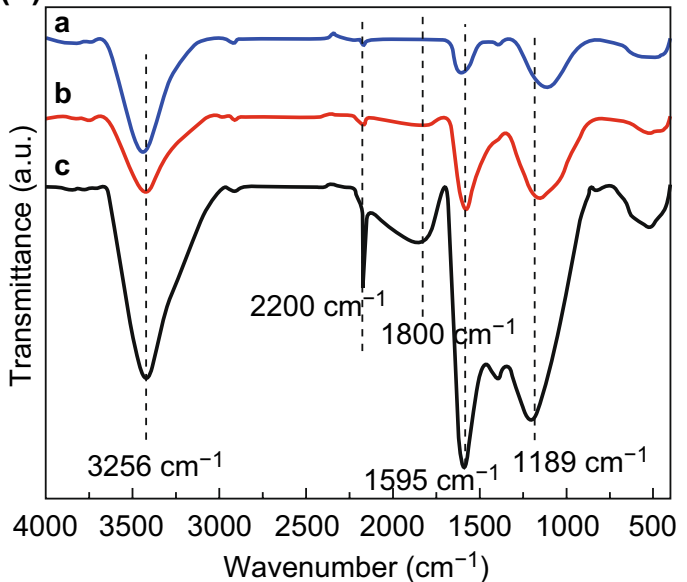

Fig. 3 A Wide-angle XRD patterns, B Raman spectra, C XPS survey spectra, D N $1 s$ XPS spectra, E O $1 s$ XPS spectra, and F FTIR spectra of HPNCF-2.0-900 (a), HPNCF-2.0-800 (b), and HPNCF-2.0-700 (c)

types I and IV (Fig. 5A), indicative of a hierarchical meso-/microporous material. Notably, at $P / P_{0}<0.1$, there is a sharp and large $\mathrm{N}_{2}$ uptake because of the $\mathrm{N}_{2}$ filling in micropores. At a $P / P_{0}$ range of $0.2-0.5$, there is a $\mathrm{N}_{2}$ condensation step with a slight H2-type hysteresis in the desorption branch, indicating the presence of uniform and small mesopores. The sample possesses an ultrahigh specific surface area of $\sim 2634 \mathrm{~m}^{2} \mathrm{~g}^{-1}$ and a large total pore 

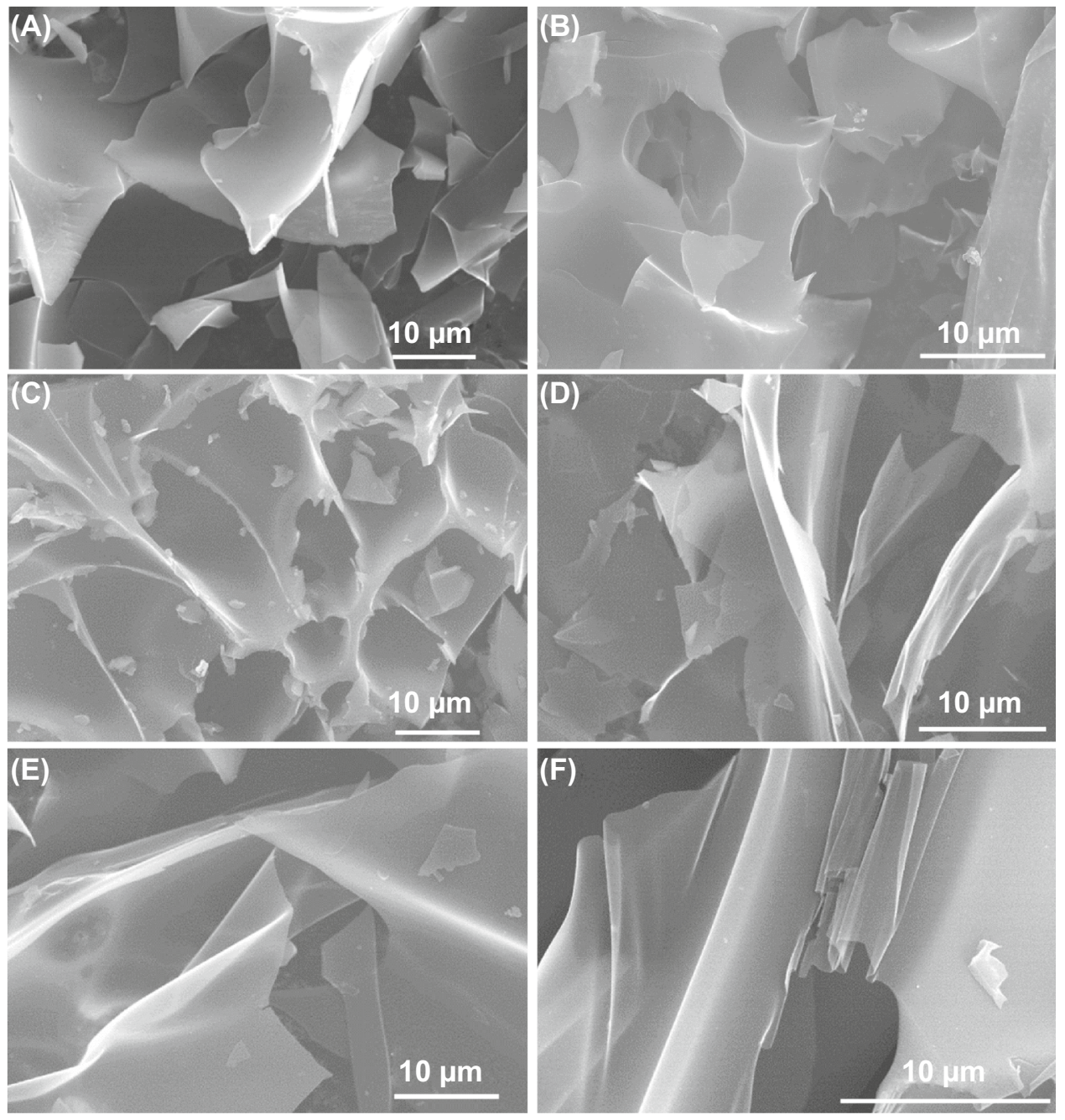

Fig. 4 SEM images of A HPNCF-2.0-700, B HPNCF-2.0-800, C HPNCF-0.75-900, D HPNCF-1.0-900, E HPNCF-1.5-900, and F HPNCF2.5-900

volume of $\sim 1.83 \mathrm{~cm}^{3} \mathrm{~g}^{-1}$. Moreover, the micropore surface area and micropore volume are up to $823 \mathrm{~m}^{2} \mathrm{~g}^{-1}$ and $0.46 \mathrm{~cm}^{3} \mathrm{~g}^{-1}$. These parameters are highly competitive compared with many HPCs in the literature (Table S1). The corresponding pore size distribution (PSD) curve of the sample reveals two narrow peaks centered at $\sim 0.91$ and $1.8 \mathrm{~nm}$ and a third peak centered at $\sim 4.0 \mathrm{~nm}$ (Fig. 5B). In a sharp contrast, the control sample prepared from His without the addition of $\mathrm{PBC}$ is predominantly microporous (pore size $<0.8 \mathrm{~nm}$ ) with a much lower surface area of $400 \mathrm{~m}^{2} \mathrm{~g}^{-1}$ and a significantly smaller pore volume of $0.25 \mathrm{~cm}^{3} \mathrm{~g}^{-1}$ (Fig. S6d). This result confirms the high efficiency of the acid-base enabled in situ chemical activation method.
All the HPNCFs obtained at $900{ }^{\circ} \mathrm{C}$ with various PBC/ His molar ratios of $0.75-2.5$ possess hierarchical meso-/ micropores (Fig. 5A-D and Table 1). The sample HPNCF$0.75-900$ is mainly microporous showing predominant type I $\mathrm{N}_{2}$ adsorption/desorption isotherms (Fig. 5A). With the increase in the $\mathrm{PBC} / \mathrm{His}$ molar ratio, the resultant samples are more obviously mesoporous, indicating the intensified chemical activation and carbon wall etching with the increase in PBC (Fig. 5A-D). With the PBC/His molar ratio increased from 0.75 to 2.5 , the total surface area increases from 2056 to $2793 \mathrm{~m}^{2} \mathrm{~g}^{-1}$, and the total pore volume increases sharply from 0.94 to $1.99 \mathrm{~cm}^{3} \mathrm{~g}^{-1}$ (Table 1). However, the micropore surface area decreases from 1611 to $760 \mathrm{~m}^{2} \mathrm{~g}^{-1}$ (Fig. 5C and Table 1), and the micropore volume 

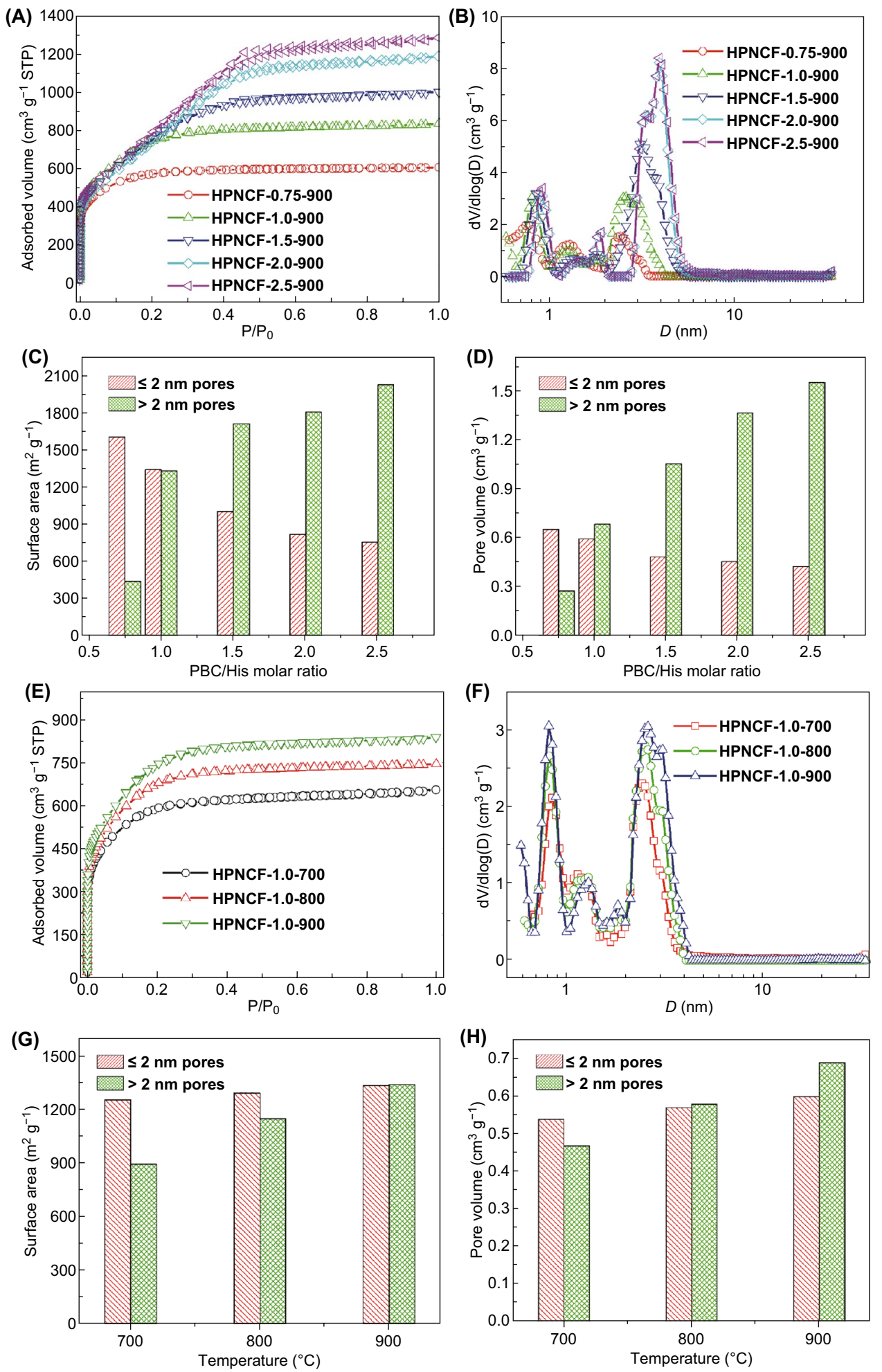

Fig. $5 \mathrm{~N}_{2}$ sorption isotherms (A, E) and the PSD curves $(\mathbf{B}, \mathbf{F})$ of the HPNCFs obtained at various PBC/His molar ratios and temperatures, and the corresponding pore-size-dependent surface area $(\mathbf{C}, \mathbf{G})$ and pore volume $(\mathbf{D}, \mathbf{H})$ variations with the increase in the $\mathrm{PBC} / \mathrm{His}$ molar ratio at a fixed temperature of $900{ }^{\circ} \mathrm{C}(\mathbf{C}, \mathbf{D})$ and with the increase in temperature at a fixed $\mathrm{PBC} / \mathrm{His}$ molar ratio of $1.0(\mathbf{G}, \mathbf{H})$ 
decreases from 0.66 to $0.43 \mathrm{~cm}^{3} \mathrm{~g}^{-1}$ (Fig. 5D and Table 1). On the other hand, with the increase in the $\mathrm{PBC} / \mathrm{His}$ molar ratio, the PSD curves show that the mesopore size increases from 2.3 to $4.0 \mathrm{~nm}$, and the micropore size also increases to some extent (Fig. 5B and Table 1). The above trends clearly confirm that the increase in PBC can enhance the chemical activation to etch more carbon walls and generate pores with increased sizes.

All the HPNCFs obtained with a fixed $\mathrm{PBC} / \mathrm{His}$ molar ratio at $700-900{ }^{\circ} \mathrm{C}$ possess similar hierarchical meso-/micropores (Fig. 5E-H, S8 and Table 1). At a low $\mathrm{PBC} / \mathrm{His}$ molar ratio of 1.0 , there are clear increasing trends for the total surface area $\left(2162-2686 \mathrm{~m}^{2} \mathrm{~g}^{-1}\right)$, micropore surface area (1261-1348 $\left.\mathrm{m}^{2} \mathrm{~g}^{-1}\right)$, total pore volume (1.01-1.29 $\left.\mathrm{cm}^{3} \mathrm{~g}^{-1}\right)$ and micropore volume $\left(0.54-0.60 \mathrm{~cm}^{3} \mathrm{~g}^{-1}\right)$ with the temperature increased from 700 to $900{ }^{\circ} \mathrm{C}$ (Fig. 5E-H, and Table 1), while the pore size increases slightly (Fig. 5F, Table 1). Differently, at a high $\mathrm{PBC} / \mathrm{His}$ molar ratio of 2.0 , with the temperature increased from 700 to $900{ }^{\circ} \mathrm{C}$, while the total pore volume $\left(1.66-1.83 \mathrm{~cm}^{3} \mathrm{~g}^{-1}\right)$ and pore size $(3.1-4.0 \mathrm{~nm})$ increases obviously, the total surface area (3209-2634 $\mathrm{m}^{2} \mathrm{~g}^{-1}$ ), micropore surface area $\left(1381-823 \mathrm{~m}^{2} \mathrm{~g}^{-1}\right)$ and micropore volume $\left(0.67-0.46 \mathrm{~cm}^{3} \mathrm{~g}^{-1}\right)$ decrease obviously (Fig. S8 and Table 1). Therefore, enhanced chemical activation generating more micropores can be achieved with the increase in temperature at a relatively low PBC dosage. Significant etching of carbon walls generating mesopores can be promoted with the increase in temperature at a relatively high PBC dosage.

\subsection{Chemical Composition and Surface Property}

Elemental analyses reveal that all the HPNCFs are composed of $\mathrm{C}$ as the main component and $\mathrm{O}, \mathrm{N}$, and $\mathrm{H}$ as the minor ones. The DF-STEM image and the corresponding elemental maps show that the elements are evenly distributed in the sample (Fig. 2K). All the samples have high $\mathrm{N}$ contents (3.9-14.6 wt\%) (Table 1), because the His precursor carries a theoretical $\mathrm{N}$ content of $22 \mathrm{wt} \%$ with a stable imidazole ring [66]. At a fixed $\mathrm{PBC} / \mathrm{His}$ molar ratio of 2.0, with the temperate increased from 700 to $900{ }^{\circ} \mathrm{C}$, the $\mathrm{N}$ content of the HPNCFs decreases from 14.52 to 6.31 $\mathrm{wt} \%$ (Table 1), because the intensive carbonization process can break down the less stable $\mathrm{N}$-containing moieties. At $900{ }^{\circ} \mathrm{C}$, the $\mathrm{N}$ content of the HPNCFs generally increases (from about 4-6 wt\%) with the increase in the $\mathrm{PBC} / \mathrm{His}$ molar ratio (Table 1). This is probably because the etching of carbon becomes increasingly intensive with the increase in PBC, rendering relatively increased $\mathrm{N}$ contents. On the other hand, all the HPNCFs possess high $\mathrm{O}$ contents of 6.12-16.90 wt\% (Table 1). With the increase in temperature, the $\mathrm{O}$ content decreases obviously. At the fixed temperature, there is a decreasing trend for the $\mathrm{O}$ content with the increase in PBC dosage. This is in agreement with the intensified carbon etching releasing $\mathrm{CO}$ and $\mathrm{CO}_{2}$ with the increase in PBC.

XPS survey spectra of the HPNCFs show three obvious bands assigned to $\mathrm{C}, \mathrm{N}$ and $\mathrm{O}$ (Fig. 3C). The $\mathrm{N}$ contents estimated from the XPS analyses are in agreement with the results from element analyses. The high-resolution $\mathrm{N}$

Table 1 Summary of the textural properties and the N and O contents of the HPNCFs obtained at various PBC/His molar ratios and temperatures

\begin{tabular}{lllllllrr}
\hline Sample name & $S_{\mathrm{BET}}\left(\mathrm{m}^{2} \mathrm{~g}^{-1}\right)$ & $\begin{array}{l}S_{\text {micropore }} \\
\left(\mathrm{m}^{2} \mathrm{~g}^{-1}\right)\end{array}$ & $V_{\text {total }}\left(\mathrm{cm}^{3} \mathrm{~g}^{-1}\right)$ & $\begin{array}{l}V_{\text {micropore }} \\
\left(\mathrm{cm}^{3} \mathrm{~g}^{-1}\right)\end{array}$ & Micropore (nm) & Mesopore (nm) & N (wt\%) & O (wt\%) \\
\hline HPNCF-0.75-900 & 2056 & 1611 & 0.94 & 0.66 & $0.77,1.3$ & 2.3 & 7.71 \\
HPNCF-1.0-900 & 2686 & 1348 & 1.29 & 0.60 & $0.82,1.3,1.8$ & 2.6 & 3.91 \\
HPNCF-1.5-900 & 2730 & 1011 & 1.55 & 0.49 & $0.86,1.4,1.8$ & 3.3 & 4.62 & 11.87 \\
HPNCF-2.0-900 & 2634 & 823 & 1.83 & 0.46 & $0.91,1.4,1.8$ & 4.0 & 5.29 & 9.60 \\
HPNCF-2.5-900 & 2793 & 760 & 1.99 & 0.43 & $0.92,1.5,1.9$ & 4.0 & 6.31 \\
HPNCF-1.0-700 & 2162 & 1261 & 1.01 & 0.54 & $0.85,1.1$ & 2.4 & 5.90 & 6.12 \\
HPNCF-1.0-800 & 2452 & 1298 & 1.15 & 0.57 & $0.82,1.2$ & 2.5 & 14.62 \\
HPNCF-2.0-700 & 3209 & 1381 & 1.66 & 0.67 & $0.88,1.8$ & 3.1 & 16.90 \\
HPNCF-2.0-800 & 2305 & 730 & 1.52 & 0.39 & $0.91,1.8$ & 3.9 & 14.10 \\
\hline
\end{tabular}


1s XPS spectra of the HPNCFs obtained at $700-900{ }^{\circ} \mathrm{C}$ can be well fitted into three component peaks centered at 401.4, 400.1 and $398 \mathrm{eV}$ (Fig. 3D), respectively, which can be assigned to graphitic, pyrrolic and pyridinic $\mathrm{N}$, respectively. Notably, with the increase in the temperature, the content of graphitic $\mathrm{N}$ is minimized and the content pyridinic $\mathrm{N}$ decreases significantly (Fig. 3D). Normally, with the increase in heating temperature, graphitic and pyridinic $\mathrm{N}$ are the most stable $\mathrm{N}$ sites in $\mathrm{N}$-doped carbon materials. In the present case, the observed opposite trend is mostly because the enhanced chemical activation at higher temperatures breaks down the aromatic rings of the graphitic and pyridinic $\mathrm{N}$ sites. This allows a selective $\mathrm{N}$-type doping in carbon materials, which will be studied in detail in our future work. On the other hand, the high-resolution $\mathrm{O}$ $1 s$ XPS spectra (Fig. 3E) of all the HPNCFs can also be fitted into three components centered at 531.7, 532.6 and $533.7 \mathrm{eV}$, corresponding to the quinone-type oxygen $(\mathrm{C}=\mathrm{O}$, $\mathrm{O}-1)$, phenol-type oxygen $(\mathrm{C}-\mathrm{OH}$ or $\mathrm{C}-\mathrm{O}-\mathrm{C}, \mathrm{O}-2)$ and carboxyl-type oxygen (COO-, O-3), respectively. Among them, the O-2 band shows the highest intensity for all the samples. With the increase in the temperature, the O-2 and O-3 oxygen bands become weakened because of their relatively lower thermal stability.

The FTIR spectra of all the HPNCFs exhibit a broad absorption band at $3400 \mathrm{~cm}^{-1}$ with a small shoulder at $\sim 3256 \mathrm{~cm}^{-1}$ (Fig. 3F), indicating the presence of hydroxyl groups probably from the sample surface and the adsorbed water. This peak becomes weaker with the increase in temperature. A strong sharp peak at $\sim 2200 \mathrm{~cm}^{-1}$ and an obvious band at $\sim 1800 \mathrm{~cm}^{-1}$ can be observed for the sample obtained at $700{ }^{\circ} \mathrm{C}$ (Fig. 3F, curve c), mostly assigned to the $\mathrm{N}=\mathrm{C}=\mathrm{O}$ and $\mathrm{C}=\mathrm{O}$ moieties in the sample, and there might be some $\mathrm{CO}_{2}$ molecules adsorbed on the $\mathrm{N}$ sites contributing to the band at $\sim 2200 \mathrm{~cm}^{-1}$. These two bands become significantly weakened in the samples obtained at higher temperatures (Fig. 3F, curves a and b), in agreement with the elemental analyses and XPS results showing dramatically decreased $\mathrm{N}$ and $\mathrm{O}$ contents. The observed broad bands at $\sim 1189$ and at $1595 \mathrm{~cm}^{-1}$ reveal the presence of benzene rings, $\mathrm{C}-\mathrm{O}(\mathrm{O}-2)$ and $\mathrm{C}-\mathrm{N}$ bonding configurations. These two bands become gradually weakened with the increase in temperature because of the decreased $\mathrm{N}$ and $\mathrm{O}$ contents.

\subsection{Performance in Supercapacitors}

The HPNCFs are desirable for supercapacitors. They possess ultrahigh surface areas and uniform micropores for charge storage, uniform mesopores for fast mass transfer, and 3D macropores for electrolyte storage (Scheme 1F). Moreover, their $\mathrm{O}$ - and $\mathrm{N}$-containing groups can facilitate the infiltration and diffusion of aqueous electrolytes. These groups can also provide oxidation-reduction pathways, which can supply faradaic pseudocapacitance.

The CV curves of the electrode made of the typical sample HPNCF-2.0-900 shows a quasi-rectangular shape over a scan rate of $5-100 \mathrm{mV} \mathrm{s}^{-1}$ in a potential window of -1.0 to $0 \mathrm{~V}$ by using a 6.0-M KOH aqueous electrolyte (Fig. 6A), indicating a typical characteristic of electrical double-layer capacitance (EDLC). At the scan rate of $5 \mathrm{mV} / \mathrm{s}$, there are small and weak redox peaks in the CV curve at $\sim-0.4 \mathrm{~V}$ (Fig. S9), mostly because of the redox reactions induced by the $\mathrm{N}$ - and $\mathrm{O}$-containing groups. The GCD curves of the HPNCF-2.0-900 electrode at the current densities of $0.5-30 \mathrm{~A} \mathrm{~g}^{-1}$ show similar isosceles triangle shapes with no obvious IR drop (Fig. 6B), indicating a high rate capability. The specific capacitance of the HPNCF-2.0-900 sample at a current density of $0.5 \mathrm{~A} \mathrm{~g}^{-1}$ is $\sim 222 \mathrm{~F} \mathrm{~g}^{-1}$. At the high current density of $30 \mathrm{~A} \mathrm{~g}^{-1}$, a high specific capacitance of $\sim 150 \mathrm{~F} \mathrm{~g}^{-1}\left(\sim 68 \%\right.$ of the capacitance at $\left.0.5 \mathrm{~A} \mathrm{~g}^{-1}\right)$ can be maintained (Fig. 6C). Such performance is better than or comparable to those of many reported $\mathrm{N}$-doped carbon materials (Table S1). In the Nyquist plot of the HPNCF2.0-900 electrode, there is no visible semicircle in the high-frequency range, and a steep line nearly parallel to the vertical axis can be observed in the low-frequency region (Fig. 6E), indicative of a fast charge transfer and ionic diffusion process and a typical double-layer capacitance behavior $[68,69]$. From the intercept on the $\mathrm{X}$-axis, the equivalent series resistance (ESR), which reflects the electrolyte ionic resistance, the working electrode electronic resistance and contact resistance at the interface of electrode/electrolyte [70], is only $\sim 0.67 \Omega$. To further evaluate the impedance of electrochemical system, in the equivalent circuit, $R_{\mathrm{S}}$ (the cell resistance of electrolyte and electrode) is only $\sim 0.68$ $\Omega$, and $R_{\mathrm{ct}}$ (the charge transfer resistance) is only $\sim 2.36 \Omega$ (Fig. S10a), verifying that excellent charge transfer with a low resistance can be proceeded on the HPNCF-2.0-900 

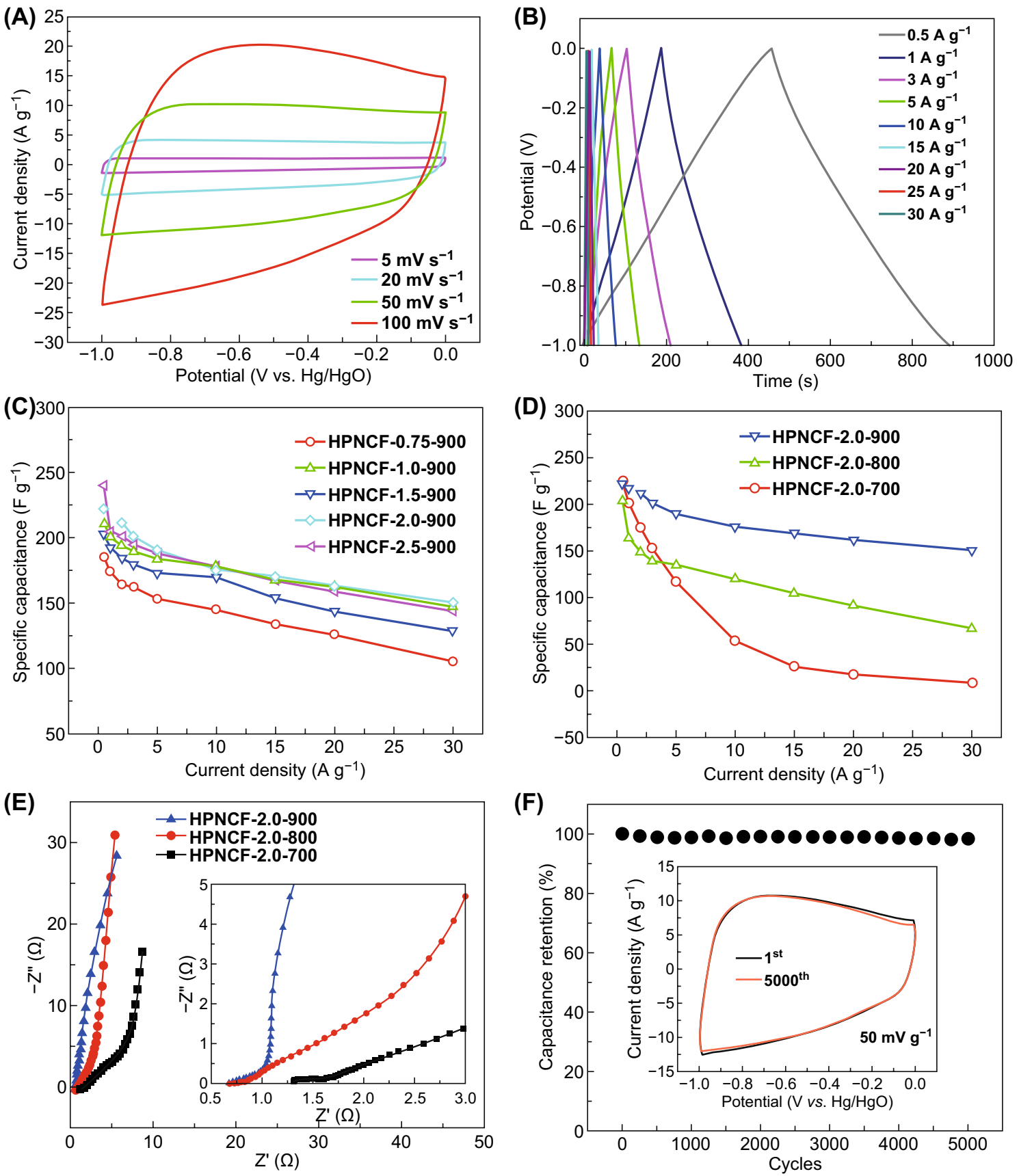

Fig. 6 A CV and B GCD curves, and F cycling test of the electrode made of the sample HPNCF-2.0-900. C Rate capability of the HPNCFs obtained at various $\mathrm{PBC} / \mathrm{His}$ molar ratios with a fixed temperature of $900{ }^{\circ} \mathrm{C}$. D, E Rate capability and Nyquist plots of the HPNCFs obtained at various temperatures with a fixed $\mathrm{PBC} / \mathrm{His}$ molar ratio of 2.0

electrode. The rapid charge transfer is closely related to the structural features of HPNCF-2-900; that is, the 3D macroporous carbon network with hierarchal meso-/ micropores can host large amount of electrolytes with a high wettability, provide abundant and accessible sites for charge storage and shorten the transfer paths of electrons and ions (Scheme 1F) $[6,28]$. These features also make the HPNCF-2-900 electrode very stable. After 5000 cycles, the CV curves keep the same (inset in Fig. 6F), and only a slight capacitance loss of $1.84 \%$ can be observed (Fig. $6 \mathrm{~F}$ ). 
The temperature influences the supercapacitor performance significantly of the resultant HPNCFs. The sample obtained at $800{ }^{\circ} \mathrm{C}$ shows quasi-rectangular $\mathrm{CV}$ curves at low scan rates, but the $\mathrm{CV}$ curves are much distorted at high scan rates (Fig. $\mathrm{S} 11 \mathrm{~b})$. Distorted CV curves can be observed for the sample obtained at $700{ }^{\circ} \mathrm{C}$ at all scan rates (Fig. S11a). The specific capacitances of the samples obtained at 700-900 ${ }^{\circ} \mathrm{C}$ at a low current density of $0.5 \mathrm{~A} \mathrm{~g}^{-1}$ are close (204-225 $\mathrm{F} \mathrm{g}^{-1}$ ) (Fig. 6D). However, the capacitance maintains only 33 and $4 \%$ for the samples obtained at 800 and $700{ }^{\circ} \mathrm{C}$ (Fig. 6D), respectively, indicative of their poor rate capabilities because of their low electronic conductivity and large electric resistance. The Nyquist plot for the sample obtained at $700{ }^{\circ} \mathrm{C}$ shows a semicircle at the high-frequency region (Fig. 6E). In the lowfrequency region, the samples obtained at 800 and $700{ }^{\circ} \mathrm{C}$ show small slopes for the straight lines (Fig. 6E). The ESR is estimated to be 0.79 and $1.32 \Omega$ for the sample obtained at 800 and $700{ }^{\circ} \mathrm{C}$. Besides, from the equivalent circuits (Fig. S10b,
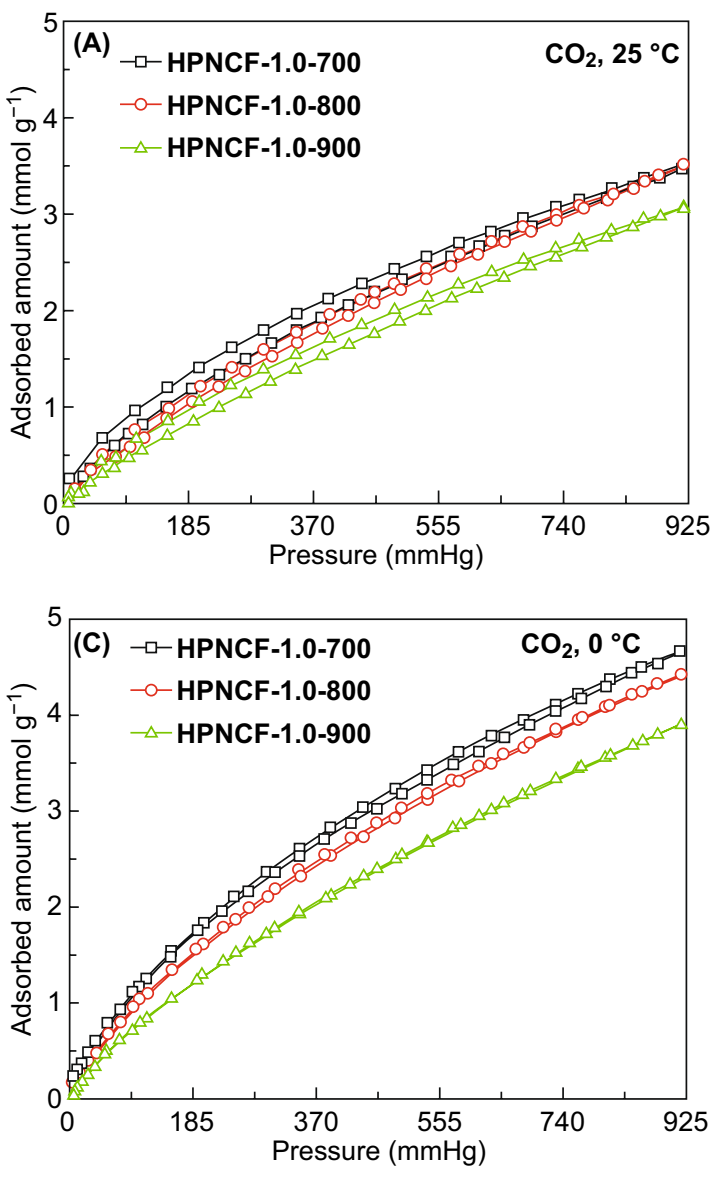

c), the $R_{\mathrm{s}}$ values for the samples obtained at 800 and $700{ }^{\circ} \mathrm{C}$ are 0.80 and $1.42 \Omega$, and the $R_{\text {ct }}$ values are up to $\sim 70$ and $1750 \Omega$, respectively. The above results reveal that the electrical resistance increases significantly for samples obtained at low temperatures, thus leading to the low rate capability.

For the HPNCFs samples obtained at various $\mathrm{PBC} / \mathrm{His}$ molar ratios $(0.75-2.5)$ at $900{ }^{\circ} \mathrm{C}$, their specific capacitances are close $\left(185-240 \mathrm{~F} \mathrm{~g}^{-1}\right)$ at a current density of $0.5 \mathrm{~A} \mathrm{~g}^{-1}$ (Fig. 6C). Generally, the samples obtained at high PBC/His molar ratios possess relatively higher specific capacitances, probably due to the enhanced surface areas. On the other hand, their rate capability is similar, with $60-70 \%$ capacitance retained at $30 \mathrm{~A} \mathrm{~g}^{-1}$ (Fig. 6C), because these samples possess similar hierarchical macro-/meso-/micropores, as well as similar chemical compositions. These results indicate that the HPNCFs obtained at $900{ }^{\circ} \mathrm{C}$ are attractive for charge storage because of their hierarchical porosity, high surface areas and low electronic resistance.
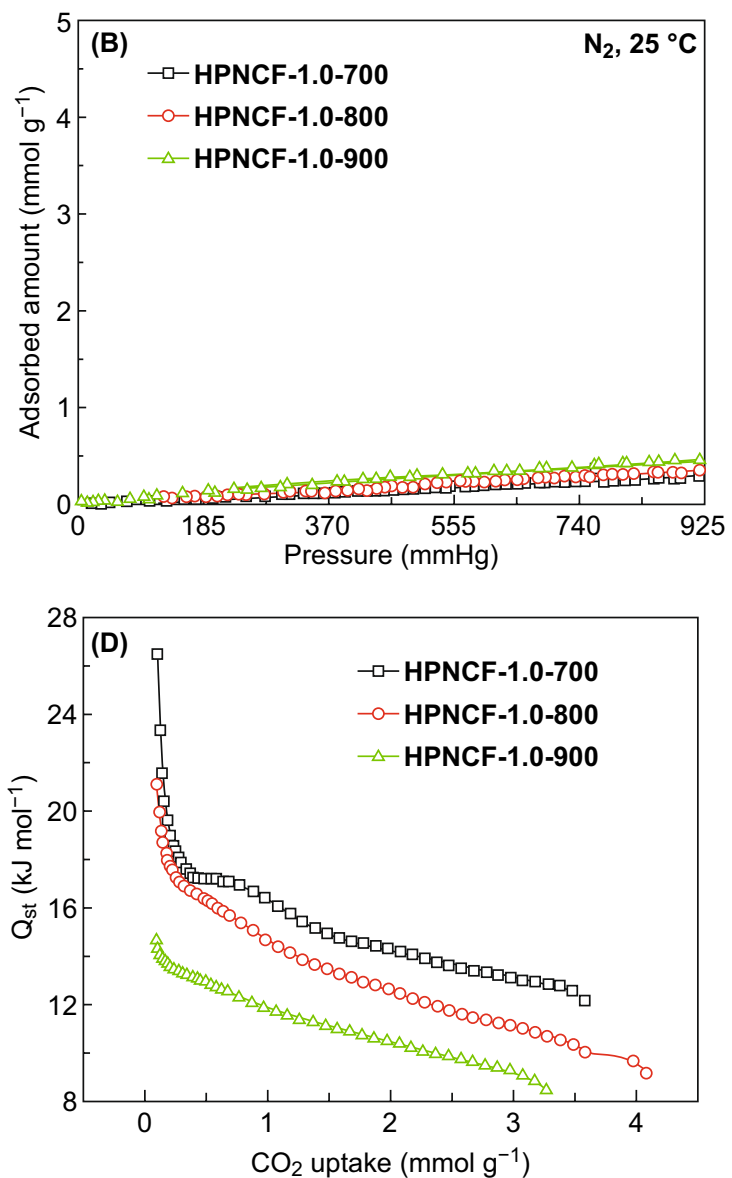

Fig. $7 \mathrm{CO}_{2}(\mathbf{A}, \mathbf{C})$ and $\mathrm{N}_{2}(\mathbf{B})$ sorption isotherms at $25(\mathbf{A}, \mathbf{B})$ and $0{ }^{\circ} \mathrm{C}(\mathbf{C})$, and the corresponding isosteric heat of adsorption curves $(\mathbf{D})$ of HPNCF-1.0-700, HPNCF-1.0-800, and HPNCF-1.0-900 


\section{6 $\mathrm{CO}_{2}$ Capture Performance}

The HPNCFs possess high surface areas, large micropore volumes and high $\mathrm{N}$ contents. These features make them promising for $\mathrm{CO}_{2}$ capture [71-74]. The HPNCFs obtained with a $\mathrm{PBC} / \mathrm{His}$ molar ratio of 1.0 at $700-900{ }^{\circ} \mathrm{C}$ are typical for $\mathrm{CO}_{2}$ capture because they are mainly microporous (Table 1). The $\mathrm{CO}_{2}$ adsorption isotherms at $25{ }^{\circ} \mathrm{C}$ of the sample HPNCF-1.0-700 show gradual uptake of $\mathrm{CO}_{2}$ with the increase in pressure, and a high adsorption capacity of $\sim 3.1 \mathrm{mmol} \mathrm{g}^{-1}$ can be achieved at a $\mathrm{CO}_{2}$ pressure of 760 torr (Fig. 7A, and Table 2). The adsorption capacity at a $\mathrm{CO}_{2}$ pressure of 114 torr, the normal $\mathrm{CO}_{2}$ partial pressure of industrial flue gas, is up to $\sim 0.81 \mathrm{mmol} \mathrm{g}^{-1}$. The adsorption capacities at these two pressures can be increased to $\sim 4.13$ and $1.27 \mathrm{mmol} \mathrm{g}^{-1}$ at an adsorption temperature of $0{ }^{\circ} \mathrm{C}$ (Fig. $7 \mathrm{C}$, and Table 2). The $\mathrm{CO}_{2}$ adsorption capacity of the HPNCFs decreases with the increase in the temperature from 700 to $900{ }^{\circ} \mathrm{C}$ (Fig. 7A, $\mathrm{C}$ ), in spite of the increase in the total surface area and pore volume (Table 1). This is because $\mathrm{CO}_{2}$ is a small acidic molecule and its adsorption capacity is more related to the micropore surface area and the $\mathrm{N}$ content. The sample obtained at $700{ }^{\circ} \mathrm{C}$ possesses the highest micropore surface area and $\mathrm{N}$ content, thus showing the best $\mathrm{CO}_{2}$ adsorption capacity. Because of the strong interactions of $\mathrm{CO}_{2}$ molecules with the $\mathrm{N}$ sites and micropore walls, the sample obtained at $700{ }^{\circ} \mathrm{C}$ also shows the highest $\mathrm{CO}_{2}$ isosteric heat of adsorption, up to $\sim 26.5 \mathrm{~kJ} \mathrm{~mol}^{-1}$, about two times of that for the sample obtained at $900{ }^{\circ} \mathrm{C}$ (Fig. 7D). On the other hand, the adsorption capacities of $\mathrm{N}_{2}$ on the above HPNCFs samples are quite low (Fig. 7B), because of the weak interactions between $\mathrm{N}_{2}$ and the adsorbents. As a result, an excellent $\mathrm{CO}_{2} / \mathrm{N}_{2}$ adsorption

Table 2 Summary of the $\mathrm{CO}_{2}$ capture performance of the typical HPNCFs

\begin{tabular}{|c|c|c|c|c|c|}
\hline \multirow[t]{2}{*}{ Sample name } & \multicolumn{2}{|c|}{$\begin{array}{l}\mathrm{CO}_{2} \text { capacity at } \\
25^{\circ} \mathrm{C}\end{array}$} & \multicolumn{2}{|c|}{$\begin{array}{l}\mathrm{CO}_{2} \text { capacity at } \\
0{ }^{\circ} \mathrm{C}\end{array}$} & \multirow{2}{*}{$\begin{array}{l}\mathrm{CO}_{2} / \mathrm{N}_{2} \\
\text { selectivity at } \\
25^{\circ} \mathrm{C}\end{array}$} \\
\hline & 114 torr & 760 torr & 114 torr & 760 torr & \\
\hline $\begin{array}{l}\text { HPNCF-1.0- } \\
\quad 700\end{array}$ & 0.81 & 3.06 & 1.27 & 4.13 & 24.0 \\
\hline $\begin{array}{l}\text { HPNCF-1.0- } \\
800\end{array}$ & 0.69 & 3.04 & 1.07 & 3.93 & 17.3 \\
\hline $\begin{array}{l}\text { HPNCF-1.0- } \\
900\end{array}$ & 0.56 & 2.63 & 0.83 & 3.41 & 9.0 \\
\hline
\end{tabular}

selectivity of $\sim 24$ at $25{ }^{\circ} \mathrm{C}$ on the sample obtained at $700{ }^{\circ} \mathrm{C}$ can be achieved (Table 2). The adsorption selectivity for the HPNCFs decreases with the increase in the temperature (Table 2), which is because of the much decreased $\mathrm{N}$ content and micropore surface area. The $\mathrm{CO}_{2}$ capture performance $\left(\mathrm{CO}_{2}\right.$ adsorption capacity and $\mathrm{CO}_{2} / \mathrm{N}_{2}$ adsorption selectivity) of the typical HPNCFs is competitive among typical $\mathrm{N}$-doped HPCs (Table $\mathrm{S} 1$ ). In addition, during cyclic tests in $\mathrm{CO}_{2}$ capture on the typical sample HPNCF-1.0-700 (Fig. S12), both rapid adsorption and desorption of $\mathrm{CO}_{2}$ processes can be observed, indicative of a predominant physisorption. After six adsorption-desorption cycles, $92 \%$ of the initial adsorption capacity can be retained, indicating a high cyclic stability for $\mathrm{CO}_{2}$ capture.

\section{Conclusions}

In summary, novel HPNCFs have been synthesized by the acid-base enabled in situ foaming and activation strategy. The key of the strategy is the self-foaming nature of His and the $\mathrm{CO}_{2}$ releasing behavior of $\mathrm{PBC}$ allowing the formation of $3 \mathrm{D}$ foam structure and the acid-base reaction enabling a molecular mixing for in situ chemical activation. With the increase in temperature, His undergoes gradual carbonization with high $\mathrm{N}$ contents sustained. Simultaneously, phase evolutions from $\mathrm{PBC}$ to $\mathrm{K}_{2} \mathrm{CO}_{3} \cdot 1.5 \mathrm{H}_{2} \mathrm{O}$ and $\mathrm{K}_{2} \mathrm{CO}_{3}$ and then to $\mathrm{K}_{2} \mathrm{O}$ and $\mathrm{K}$ are elucidated. The $\mathrm{K}$-containing substances can in situ react with carbon walls to achieve uniform chemical activation. The HPNCFs possess 3D macroporous frameworks with thin well-graphitized carbon walls, ultrahigh surface areas (2056-3200 $\mathrm{m}^{2} \mathrm{~g}^{-1}$ ), high micropore surface areas $\left(760-1611 \mathrm{~m}^{2} \mathrm{~g}^{-1}\right)$, large pore volumes $\left(0.94-2.0 \mathrm{~cm}^{3}\right.$ $\left.\mathrm{g}^{-1}\right)$, high micropore volumes $\left(0.39-0.67 \mathrm{~cm}^{3} \mathrm{~g}^{-1}\right)$, narrowly distributed micropores $(0.8-1.9 \mathrm{~nm})$ and mesopores (2.3-4.0 nm), and high $\mathrm{N}$ contents (3.9-14.6 wt\%) with pyrrolic $\mathrm{N}$ as the predominant $\mathrm{N}$ site. The increase in the $\mathrm{PBC} /$ His ratio results in increases in total surface area, total pore volume, pore size and $\mathrm{N}$ content, but decreases in micropore surface area, micropore volume and carbon wall thickness. The increase in temperature results in sharp decreases in carbon wall thickness and $\mathrm{N}$ content. The temperature increase induces enhancement for all the textural parameters at low $\mathrm{PBC} / \mathrm{His}$ ratios, while it leads to increase in pore volume and pore size but decrease in surface area at high $\mathrm{PBC} / \mathrm{His}$ ratios. The HPNCFs are promising for supercapacitors and $\mathrm{CO}_{2}$ 
capture. The HPNCFs obtained at $900{ }^{\circ} \mathrm{C}$ show high specific capacitance $\left(185-240 \mathrm{~F} \mathrm{~g}^{-1}\right)$, good rate capability and excellent stability due to the high surface area for charge storage, low electric resistance and short paths for fast electrolyte and electron transfer. The HPNCFs obtained at $700{ }^{\circ} \mathrm{C}$ show a high $\mathrm{CO}_{2}$ adsorption capacity $\left(4.13\right.$ and $1.27 \mathrm{mmol} \mathrm{g}^{-1}$ at 114 and 760 torr), a large isosteric heat of adsorption $\left(26.5 \mathrm{~kJ} \mathrm{~mol}^{-1}\right)$ and an excellent $\mathrm{CO}_{2} / \mathrm{N}_{2}$ adsorption selectivity ( 24). Finally, the in situ foaming and activation strategy may be extended for the synthesis of other carbon-based hierarchical structures for various applications.

Acknowledgements Financial support from the National Natural Science Foundation of China (Nos. 21875153, 21501125), the Natural Science Foundation of Jiangsu Province (BK20150312), and the Jiangsu Shuangchuang Team Program is appreciated. We also thank the Priority Academic Program Development (PAPD) of Jiangsu Higher Education Institutions and the Project of Scientific and Technologic Infrastructure of Suzhou (SZS201708) for support.

Open Access This article is licensed under a Creative Commons Attribution 4.0 International License, which permits use, sharing, adaptation, distribution and reproduction in any medium or format, as long as you give appropriate credit to the original author(s) and the source, provide a link to the Creative Commons licence, and indicate if changes were made. The images or other third party material in this article are included in the article's Creative Commons licence, unless indicated otherwise in a credit line to the material. If material is not included in the article's Creative Commons licence and your intended use is not permitted by statutory regulation or exceeds the permitted use, you will need to obtain permission directly from the copyright holder. To view a copy of this licence, visit http://creativecommons.org/licenses/by/4.0/

Electronic supplementary material The online version of this article (https://doi.org/10.1007/s40820-020-0389-3) contains supplementary material, which is available to authorized users.

\section{References}

1. J. Liu, N.P. Wickramaratne, S.Z. Qiao, M. Jaroniec, Molecular-based design and emerging applications of nanoporous carbon spheres. Nat. Mater. 14, 763-774 (2015). https://doi. org/10.1038/nmat4317

2. L.L. Zhang, X.S. Zhao, Carbon-based materials as supercapacitor electrodes. Chem. Soc. Rev. 38, 2520-2531 (2009). https://doi.org/10.1039/B813846J

3. A.S. Arico, P. Bruce, B. Scrosati, J.M. Tarascon, W. Van Schalkwijk, Nanostructured materials for advanced energy conversion and storage devices. Nat. Mater. 4, 366-377 (2005). https://doi.org/10.1142/9789814317665_0022
4. D.W. Wang, F. Li, M. Liu, G.Q. Lu, H.-M. Cheng, 3D aperiodic hierarchical porous graphitic carbon material for high-rate electrochemical capacitive energy storage. Angew. Chem. Int. Ed. 47, 373-376 (2008). https://doi.org/10.1002/ anie. 200702721

5. Z. Wu, D. Zhao, Ordered mesoporous materials as adsorbents. Chem. Commun. 47, 3332-3338 (2011). https://doi. org/10.1039/c0cc04909c

6. S.H. Lee, J. Kim, D.Y. Chung, J.M. Yoo, H.S. Lee et al., Design principle of $\mathrm{Fe}-\mathrm{N}-\mathrm{C}$ electrocatalysts: how to optimize multimodal porous structures? J. Am. Chem. Soc. 141, 2035-2045 (2019). https://doi.org/10.1021/jacs.8b11129

7. H. Tian, J. Liang, J. Liu, Nanoengineering carbon spheres as nanoreactors for sustainable energy applications. Adv. Mater. 31, e1903886 (2019). https://doi.org/10.1002/ adma.201903886

8. P. Simon, Y. Gogotsi, Materials for electrochemical capacitors. Nat. Mater. 7, 845-854 (2008). https://doi. org/10.1142/9789814287005_0033

9. S. Kondrat, C.R. Pérez, V. Presser, Y. Gogotsi, A.A. Kornyshev, Effect of pore size and its dispersity on the energy storage in nanoporous supercapacitors. Energy Environ. Sci. 5, 6474 (2012). https://doi.org/10.1039/c2ee03092f

10. M. Sevilla, G.A. Ferrero, N. Diez, A.B. Fuertes, One-step synthesis of ultra-high surface area nanoporous carbons and their application for electrochemical energy storage. Carbon 131, 193-200 (2018). https://doi.org/10.1016/j.carbo n.2018.02.021

11. A.E. Creamer, B. Gao, Carbon-based adsorbents for postcombustion $\mathrm{CO}_{2}$ capture: a critical review. Environ. Sci. Technol. 50, 7276-7289 (2016). https://doi.org/10.1021/acs.est.6b006 27

12. J. Wang, L. Huang, R. Yang, Z. Zhang, J. Wu, Y. Gao, Q. Wang, D. O'Hare, Z. Zhong, Recent advances in solid sorbents for $\mathrm{CO}_{2}$ capture and new development trends. Energy Environ. Sci. 7, 3478-3518 (2014). https://doi.org/10.1039/ C4EE01647E

13. M. Sevilla, A.S.M. Al-Jumialy, A.B. Fuertes, R. Mokaya, Optimization of the pore structure of biomass-based carbons in relation to their use for $\mathrm{CO}_{2}$ capture under low- and highpressure regimes. ACS Appl. Mater. Interfaces 10, 1623-1633 (2018). https://doi.org/10.1021/acsami.7b10433

14. L. Zhang, X. Yang, F. Zhang, G. Long, T. Zhang et al., Controlling the effective surface area and pore size distribution of $s p^{2}$ carbon materials and their impact on the capacitance performance of these materials. J. Am. Chem. Soc. 135, 59215929 (2013). https://doi.org/10.1021/ja402552h

15. D. Bhattacharjya, M.-S. Kim, T.-S. Bae, J.-S. Yu, High performance supercapacitor prepared from hollow mesoporous carbon capsules with hierarchical nanoarchitecture. J. Power Sources 244, 799-805 (2013). https://doi.org/10.1016/j.jpows our.2013.01.112

16. T.Q. Lin, I.W. Chen, F.X. Liu, C.Y. Yang, H. Bi, F.F. Xu, F.Q. Huang, Nitrogen-doped mesoporous carbon of extraordinary capacitance for electrochemical energy storage. Science $\mathbf{3 5 0}$, 1508-1513 (2015). https://doi.org/10.1126/science.aab3798 
17. L. Yao, Q. Wu, P. Zhang, J. Zhang, D. Wang et al., Scalable 2D hierarchical porous carbon nanosheets for flexible supercapacitors with ultrahigh energy density. Adv. Mater. 30, 1706054 (2018). https://doi.org/10.1002/adma.201706054

18. X.Y. Yang, L.H. Chen, Y. Li, J.C. Rooke, C. Sanchez, B.L. $\mathrm{Su}$, Hierarchically porous materials: synthesis strategies and structure design. Chem. Soc. Rev. 46, 481-558 (2017). https ://doi.org/10.1039/C6CS00829A

19. Y.X. Xu, Z.Y. Lin, X. Zhong, X.Q. Huang, N.O. Weiss, Y. Huang, X.F. Duan, Holey graphene frameworks for highly efficient capacitive energy storage. Nat. Commun. 5, 4554 (2014). https://doi.org/10.1038/ncomms5554

20. Y.X. Xu, C.Y. Chen, Z.P. Zhao, Z.Y. Lin, C. Lee et al., Solution processable holey graphene oxide and its derived macrostructures for high-performance supercapacitors. Nano Lett. 15, 4605-4610 (2015). https://doi.org/10.1021/acs.nanol ett. $5 \mathrm{~b} 01212$

21. T. Guan, J. Zhao, G. Zhang, J. Wang, D. Zhang, K. Li, Template-free synthesis of honeycomblike porous carbon rich in specific 2-5 $\mathrm{nm}$ mesopores from a pitch-based polymer for a high-performance supercapacitor. ACS Sustain. Chem. Eng. 7, 2116-2126 (2019). https://doi.org/10.1021/acssuschem eng.8b04736

22. L. Miao, X. Qian, D. Zhu, T. Chen, G. Ping et al., From interpenetrating polymer networks to hierarchical porous carbons for advanced supercapacitor electrodes. Chin. Chem. Lett. 30, 1445-1449 (2019). https://doi.org/10.1016/j.cclet.2019.03.010

23. G. Qu, S. Jia, H. Wang, F. Cao, L. Li et al., Asymmetric supercapacitor based on porous $\mathrm{N}$-doped carbon derived from pomelo peel and $\mathrm{NiO}$ arrays. ACS Appl. Mater. Interfaces 8, 20822-20830 (2016). https://doi.org/10.1021/acsami.6b06630

24. M. Karnan, K. Subramani, N. Sudhan, N. Ilayaraja, M. Sathish, Aloe vera derived activated high-surface-area carbon for flexible and high-energy supercapacitors. ACS Appl. Mater. Interfaces 8, 35191-35202 (2016). https://doi.org/10.1021/acsam i.6b10704

25. C.Y. Zhang, X.H. Zhu, M. Cao, M.L. Li, N. Li, L.Q. Lai, J.L. Zhu, D.C. Wei, Hierarchical porous carbon materials derived from sheep manure for high-capacity supercapacitors. ChemSusChem 9, 932-937 (2016). https://doi.org/10.1002/ cssc. 201501624

26. C.J. Chen, Y. Zhang, Y.J. Li, J.Q. Dai, J.W. Song et al., Allwood, low tortuosity, aqueous, biodegradable supercapacitors with ultra-high capacitance. Energy Environ. Sci. 10, 538-545 (2017). https://doi.org/10.1039/C6EE03716J

27. X. Dong, H. Jin, R. Wang, J. Zhang, X. Feng et al., High volumetric capacitance, ultralong life supercapacitors enabled by waxberry-derived hierarchical porous carbon materials. Adv. Energy Mater. 8, 1702695 (2018). https://doi.org/10.1002/ aenm.201702695

28. Q. Zhang, K. Han, S. Li, M. Li, J. Li, K. Ren, Synthesis of garlic skin-derived 3D hierarchical porous carbon for highperformance supercapacitors. Nanoscale 10, 2427-2437 (2018). https://doi.org/10.1039/C7NR07158B

29. L. Gao, L. Xiong, D. Xu, J. Cai, L. Huang, J. Zhou, L. Zhang, Distinctive construction of chitin-derived hierarchically porous carbon microspheres/polyaniline for high-rate supercapacitors. ACS Appl. Mater. Interfaces 10, 28918-28927 (2018). https://doi.org/10.1021/acsami.8b058 91

30. T. Kesavan, M. Sasidharan, Palm spathe derived N-doped carbon nanosheets as a high performance electrode for Liion batteries and supercapacitors. ACS Sustain. Chem. Eng. 7, 12160-12169 (2019). https://doi.org/10.1021/acssuschem eng.9b01261

31. L. Peng, Y. Liang, J. Huang, L. Xing, H. Hu, Y. Xiao, H. Dong, Y. Liu, M. Zheng, Mixed-biomass wastes derived hierarchically porous carbons for high-performance electrochemical energy storage. ACS Sustain. Chem. Eng. 7, 10393-10402 (2019). https://doi.org/10.1021/acssuschem eng.9b00477

32. X. Peng, L. Zhang, Z. Chen, L. Zhong, D. Zhao et al., Hierarchically porous carbon plates derived from wood as bifunctional ORR/OER electrodes. Adv. Mater. 31, 1900341 (2019). https://doi.org/10.1002/adma.201900341

33. Y. Liu, M. Zhang, L. Wang, Y. Hou, C. Guo, H. Xin, S. Xu, A biomass carbon material with microtubule bundling and natural O-doping derived from goldenberry calyx and its electrochemical performance in supercapacitor. Chin. Chem. Lett. (2019). https://doi.org/10.1016/j.cclet.2019.05.045

34. C. Xuan, Z. Peng, J. Wang, W. Lei, K. Xia, Z. Wu, W. Xiao, D. Wang, Biomass derived nitrogen doped carbon with porous architecture as efficient electrode materials for supercapacitors. Chin. Chem. Lett. 28, 2227-2230 (2017). https://doi. org/10.1016/j.cclet.2017.09.009

35. P. Han, S.-H. Chung, A. Manthiram, Pyrrolic-type nitrogendoped hierarchical macro/mesoporous carbon as a bifunctional host for high-performance thick cathodes for lithium-sulfur batteries. Small 15, 1900690 (2019). https://doi.org/10.1002/ smll.201900690

36. T. Wang, Y. Sun, L. Zhang, K. Li, Y. Yi et al., Space-confined polymerization: controlled fabrication of nitrogen-doped polymer and carbon microspheres with refined hierarchical architectures. Adv. Mater. 31, e1807876 (2019). https://doi. org/10.1002/adma.201807876

37. D. Qiu, J. Guan, M. Li, C. Kang, J. Wei, Y. Li, Z. Xie, F. Wang, R. Yang, Kinetics enhanced nitrogen-doped hierarchical porous hollow carbon spheres boosting advanced potassium-ion hybrid capacitors. Adv. Funct. Mater. 29, 1903496 (2019). https://doi.org/10.1002/adfm.201903496

38. S. Sun, F. Han, X. Wu, Z. Fan, One-step synthesis of biomass derived $\mathrm{O}, \mathrm{N}$-codoped hierarchical porous carbon with high surface area for supercapacitors. Chin. Chem. Lett. (2019). https://doi.org/10.1016/j.cclet.2019.11.023

39. N.D. Petkovich, A. Stein, Controlling macro- and mesostructures with hierarchical porosity through combined hard and soft templating. Chem. Soc. Rev. 42, 3721-3739 (2013). https ://doi.org/10.1039/C2CS35308C

40. Q. Li, R. Jiang, Y. Dou, Z. Wu, T. Huang et al., Synthesis of mesoporous carbon spheres with a hierarchical pore structure for the electrochemical double-layer capacitor. 
Carbon 49, 1248-1257 (2011). https://doi.org/10.1016/j.carbo n.2010.11.043

41. T.-C. Chou, C.-H. Huang, R.-A. Doong, C.-C. Hu, Architectural design of hierarchically ordered porous carbons for high-rate electrochemical capacitors. J. Mater. Chem. A 1, 2886-2895 (2013). https://doi.org/10.1039/C2TA01190E

42. G. Hasegawa, K. Kanamori, T. Kiyomura, H. Kurata, T. Abe, K. Nakanishi, Hierarchically porous carbon monoliths comprising ordered mesoporous nanorod assemblies for high-voltage aqueous supercapacitors. Chem. Mater. 28, 3944-3950 (2016). https://doi.org/10.1021/acs.chemmater.6b01261

43. B. You, F. Kang, P. Yin, Q. Zhang, Hydrogel-derived heteroatom-doped porous carbon network for supercapacitor and electrocatalytic oxygen reduction. Carbon 103, 9-15 (2016). https://doi.org/10.1016/j.carbon.2016.03.009

44. F. Zhang, T. Liu, M. Li, M. Yu, Y. Luo, Y. Tong, Y. Li, Multiscale pore network boosts capacitance of carbon electrodes for ultrafast charging. Nano Lett. 17, 3097-3104 (2017). https ://doi.org/10.1021/acs.nanolett.7b00533

45. J. Li, L. Tian, F. Liang, J. Wang, L. Han et al., Molten salt synthesis of hierarchical porous N-doped carbon submicrospheres for multifunctional applications: high performance supercapacitor, dye removal and $\mathrm{CO}_{2}$ capture. Carbon 141, 739-747 (2019). https://doi.org/10.1016/j.carbon.2018.09.061

46. S. Zhu, L. Li, C. He, N. Zhao, E. Liu, C. Shi, M. Zhang, Soluble salt self-assembly-assisted synthesis of three-dimensional hierarchical porous carbon networks for supercapacitors. J. Mater. Chem. A 3, 22266-22273 (2015). https://doi. org/10.1039/C5TA04646G

47. F. Zhang, T. Liu, G. Hou, T. Kou, L. Yue, R. Guan, Y. Li, Hierarchically porous carbon foams for electric double layer capacitors. Nano Res. 9, 2875-2888 (2016). https://doi.org/10.1007/ s12274-016-1173-z

48. W. Li, F. Zhang, Y. Dou, Z. Wu, H. Liu et al., A self-template strategy for the synthesis of mesoporous carbon nanofibers as advanced supercapacitor electrodes. Adv. Energy Mater. 1, 382-386 (2011). https://doi.org/10.1002/aenm.201000096

49. S. Zhao, T. Yan, H. Wang, J. Zhang, L. Shi, D. Zhang, Creating $3 \mathrm{D}$ hierarchical carbon architectures with micro-, meso-, and macropores via a simple self-blowing strategy for a flowthrough deionization capacitor. ACS Appl. Mater. Interfaces 8, 18027-18035 (2016). https://doi.org/10.1021/acsami.6b037 04

50. J. Hao, Y. Liao, Y. Zhong, D. Shu, C. He et al., Three-dimensional graphene layers prepared by a gas-foaming method for supercapacitor applications. Carbon 94, 879-887 (2015). https ://doi.org/10.1016/j.carbon.2015.07.069

51. J. Hao, D. Shu, S. Guo, A. Gao, C. He et al., Preparation of three-dimensional nitrogen-doped graphene layers by gas foaming method and its electrochemical capactive behavior. Electrochim. Acta 193, 293-301 (2016). https://doi. org/10.1016/j.electacta.2016.02.048

52. J. Deng, T. Xiong, F. Xu, M. Li, C. Han, Y. Gong, H. Wang, Y. Wang, Inspired by bread leavening: one-pot synthesis of hierarchically porous carbon for supercapacitors. Green Chem. 17, 4053-4060 (2015). https://doi.org/10.1039/C5GC00523J
53. L. Guan, L. Pan, T. Peng, T. Qian, Y. Huang et al., Green and scalable synthesis of porous carbon nanosheet-assembled hierarchical architectures for robust capacitive energy harvesting. Carbon 152, 537-544 (2019). https://doi. org/10.1016/j.carbon.2019.06.05

54. N. Diez, G.A. Ferrero, M. Sevilla, A.B. Fuertes, A sustainable approach to hierarchically porous carbons from tannic acid and their utilization in supercapacitive energy storage systems. J. Mater. Chem. A 7, 14280-14290 (2019). https:// doi.org/10.1039/C9TA01712G

55. R. Shi, C. Han, H. Li, L. Xu, T. Zhang et al., NaCl-templated synthesis of hierarchical porous carbon with extremely large specific surface area and improved graphitization degree for high energy density lithium ion capacitors. J. Mater. Chem. A 6, 17057-17066 (2018). https://doi.org/10.1039/C8TA0 $5853 \mathrm{~A}$

56. J.G. Wang, H.Z. Liu, H.H. Sun, W. Hua, H.W. Wang, X.R. Liu, B.Q. Wei, One-pot synthesis of nitrogen-doped ordered mesoporous carbon spheres for high-rate and long-cycle life supercapacitors. Carbon 127, 85-92 (2018). https://doi. org/10.1016/j.carbon.2017.10.084

57. B. Li, F. Dai, Q. Xiao, L. Yang, J. Shen, C. Zhang, M. Cai, Nitrogen-doped activated carbon for a high energy hybrid supercapacitor. Energy Environ. Sci. 9, 102-106 (2016). https ://doi.org/10.1039/C5EE03149D

58. J. Zhao, H. Lai, Z. Lyu, Y. Jiang, K. Xie et al., Hydrophilic hierarchical nitrogen-doped carbon nanocages for ultrahigh supercapacitive performance. Adv. Mater. 27, 3541-3545 (2015). https://doi.org/10.1002/adma.201500945

59. K. Zou, P. Cai, C. Liu, J. Li, X. Gao et al., A kinetically wellmatched full-carbon sodium-ion capacitor. J. Mater. Chem. A 7, 13540-13549 (2019). https://doi.org/10.1039/C9TA03797G

60. J. Wei, D. Zhou, Z. Sun, Y. Deng, Y. Xia, D. Zhao, A controllable synthesis of rich nitrogen-doped ordered mesoporous carbon for $\mathrm{CO}_{2}$ capture and supercapacitors. Adv. Funct. Mater. 23, 2322-2328 (2013). https://doi.org/10.1002/ adfm.201202764

61. X. Wang, J.S. Lee, Q. Zhu, J. Liu, Y. Wang, S. Dai, Ammonia-treated ordered mesoporous carbons as catalytic materials for oxygen reduction reaction. Chem. Mater. 22, 2178-2180 (2010). https://doi.org/10.1021/cm100139d

62. Z. Wu, P.A. Webley, D. Zhao, Post-enrichment of nitrogen in soft-templated ordered mesoporous carbon materials for highly efficient phenol removal and $\mathrm{CO}_{2}$ capture. J. Mater. Chem. 22, 11379-11389 (2012). https://doi.org/10.1039/ C2JM16183D

63. Z. Song, L. Li, D. Zhu, L. Miao, H. Duan et al., Synergistic design of a $\mathrm{N}, \mathrm{O}$ co-doped honeycomb carbon electrode and an ionogel electrolyte enabling all-solid-state supercapacitors with an ultrahigh energy density. J. Mater. Chem. A 7, 816-826 (2019). https://doi.org/10.1039/C8TA10406A

64. L. Hao, J. Ning, B. Luo, B. Wang, Y. Zhang et al., Structural evolution of 2D microporous covalent triazine-based framework toward the study of high-performance supercapacitors. J. Am. Chem. Soc. 137, 219-225 (2015). https://doi. org/10.1021/ja508693y 
65. Y. Yao, Z. Chen, A. Zhang, J. Zhu, X. Wei et al., Surfacecoating synthesis of nitrogen-doped inverse opal carbon materials with ultrathin micro/mesoporous graphene-like walls for oxygen reduction and supercapacitors. J. Mater. Chem. A 5, 25237-25248 (2017). https://doi.org/10.1039/C7TA08354H

66. X. Gao, Z. Chen, Y. Yao, M. Zhou, Y. Liu et al., Direct heating amino acids with silica: a universal solvent-free assembly approach to highly nitrogen-doped mesoporous carbon materials. Adv. Funct. Mater. 26, 6649-6661 (2016). https://doi. org/10.1002/adfm.201601640

67. M.R. Benzigar, S.N. Talapaneni, S. Joseph, K. Ramadass, G. Singh et al., Recent advances in functionalized micro and mesoporous carbon materials: synthesis and applications. Chem. Soc. Rev. 47, 2680-2721 (2018). https://doi. org/10.1039/C7CS00787F

68. Z. Song, D. Zhu, L. Li, T. Chen, H. Duan et al., Ultrahigh energy density of a N, O codoped carbon nanosphere based all-solid-state symmetric supercapacitor. J. Mater. Chem. A 7, 1177-1186 (2019). https://doi.org/10.1039/C8TA10158B

69. C. Portet, G. Yushin, Y. Gogotsi, Electrochemical performance of carbon onions, nanodiamonds, carbon black and multiwalled nanotubes in electrical double layer capacitors.
Carbon 45, 2511-2518 (2007). https://doi.org/10.1016/j.carbo n.2007.08.024

70. A. Celzard, F. Collas, J.F. Mareche, G. Furdin, I. Rey, Porous electrodes-based double-layer supercapacitors: pore structure versus series resistance. J. Power Sources 108, 153-162 (2002). https://doi.org/10.1016/S0378-7753(02)00030-7

71. J.W. To, J. He, J. Mei, R. Haghpanah, Z. Chen et al., Hierarchical $\mathrm{N}$-doped carbon as $\mathrm{CO}_{2}$ adsorbent with high $\mathrm{CO}_{2}$ selectivity from rationally designed polypyrrole precursor. J. Am. Chem. Soc. 138, 1001-1009 (2016). https://doi.org/10.1021/ jacs.5b11955

72. J.H. Lee, H.J. Lee, S.Y. Lim, B.G. Kim, J.W. Choi, Combined $\mathrm{CO}_{2}$-philicity and ordered mesoporosity for highly selective $\mathrm{CO}_{2}$ capture at high temperatures. J. Am. Chem. Soc. 137, 7210-7216 (2015). https://doi.org/10.1021/jacs.5b03579

73. M. Oschatz, M.A. Antonietti, Search for selectivity to enable $\mathrm{CO}_{2}$ capture with porous adsorbents. Energy Environ. Sci. 11, 57-70 (2018). https://doi.org/10.1039/C7EE02110K

74. J. Hwang, R. Walczak, M. Oschatz, N.V. Tarakina, B. Schmidt, Micro-blooming: hierarchically porous nitrogen-doped carbon flowers derived from metal-organic mesocrystals. Small 15, e1901986 (2019). https://doi.org/10.1002/smll.201901986 